\title{
Developent and Application of Hybrid Method to Inhomogeneous Geology for Curtain Grouting -Case Study in Sedimentary Rock with Fold Movement for Nam Ngiep 1 Hydropower Project in Lao PDR-
}

Yoichi Yoshizu

NEWJEC Inc.

Kazuo Nakamura ( $\square$ nakamura.kazuo@c5.kepco.co.jp )

The Kansai Electric Power Company https://orcid.org/0000-0003-3246-4240

Tatsuya Kawata

The Kansai Electric Power Co., Inc.

Takahiro Fujii

NEWJEC Inc.

Shoji Tsutsui

NEWJEC Inc.

\section{Research Article}

Keywords: Inhomogeneous geology, Dam foundation treatment, Curtain grouting, GIN Method, Conventional Method, Hybrid Method

Posted Date: October 28th, 2021

DOI: https://doi.org/10.21203/rs.3.rs-940643/v1

License: (c) (1) This work is licensed under a Creative Commons Attribution 4.0 International License. Read Full License 


\section{Abstract}

Curtain grouting for dam foundation treatment is one of the most crucial work items in dam construction to secure the impermeability of the foundation rock. Some decades ago, the Grouting Intensity Number (GIN) Method developed in Europe has been frequently applied to relatively simple geotechnical structures. On the other hand, the Conventional Method, which requires phased mix proportion and water pressure tests through a sequence of the works, is as yet reliable for inhomogeneous geology. This paper presents the development of a modified curtain grouting method and its application to the Nam Ngiep 1 Hydropower Project in Lao PDR, which has an inhomogeneous geology of sedimentary rock with weak layers affected by fold movement. The method has been dubbed as "hybrid" because it garners both the economical superiority of the GIN Method in that it enables the use of a single mix proportion, and the technical superiority of the Conventional Method in that the individual design pressure in each stage is based on water pressure tests.

\section{Introduction}

The Nam Ngiep 1 Construction Project in Lao PDR (Tsutsui et al. 2021) includes a 167 m-high RCC dam with an alternation of sandstone and mudstone in the dam foundation rock (hereinafter 'the Site'). The curtain grouting work for the dam foundation treatment is one of the most fundamental and critical work items in the dam's construction to secure the necessary impermeability (Weaver and Bruce 1991, 2007). A few grouting methods have been developed around the world. Although the Conventional Method is as yet applied for grouting work, it requires phased mix proportion and water pressure tests through a sequence of work, and thus has a disadvantage of low construction speed due to its elaborate procedure (Kudo et al. 1984; Japan Commission on Large Dam 1957; Japan Society of Civil Engineers 1972; Ministry of Construction River Bureau 1983, 2003; lida 2002; Japan Dam Engineering Center 1987).

Some decades ago, in Europe, another concept of grouting method was introduced by Lombardi and Deer. Known as the Grouting Intensity Number (hereinafter referred to as 'GIN') Method (Lombardi 2003), it uses a single mix proportion during the entire grouting process until grouting reaches to the GIN Curve, represented by the combination of grouting pressure and injected grout volume. This has the advantages of high construction speed and low construction cost thanks to the simple procedure.

Several researches (Li et al. 2017; Shahzad. et al. 2017) have also reported that the GIN Method is more competitive than the Conventional Method in terms of cost and construction speed.

However, the GIN Method, which was applied to Nam Ngiep 1 in its early stage, was not obviously proven superior to the Conventional Method in terms of grouting time, volume and workability. This was because the weak layers in the riverbed, fold zone on the middle of right bank or vertical cracks at high elevation on both the banks due to toppling. It is supposed that, due to the high-pressurized injection of the GIN Method, cracking would be induced in the inhomogeneous geology, where crustal forces caused 
misalignment and folding of geological layers. The authors, therefore, set out to develop an innovative, competitive and economically feasible method that would fit the inhomogeneous geology on Site.

This paper introduces a new method, named the "Hybrid Method" that has the advantage of both the Conventional and the GIN Methods, and proposes its applicable geological conditions.

\section{Site Geology}

The geology on Site is composed of an alternation of sandstone and mudstone of the Jurassic to Cretaceous ages as shown in Fig. 1 (Murakami et al. 2017). Conglomerate is mainly distributed on the higher elevation of the left bank with thin mudstone layers bedded at nearly horizontal intervals of a few meters.

Each bed in the alternated beds tends to behave independently, resulting in geological separation at the contact plane (bedding plane). At the same time, the separation might have been considerably damaged by orogenic fold movement. Later, a river course stepped across the fold axis and the river down-cutting continued to create a gorge. On both the riverbanks except for the fold zone shown in Fig. 1, toppling phenomenon occurred due to gravitational movement along the two-sets of vertical geological cracks and horizontal bedding planes. The vertical cracks developed with spacing at a few meters parallel and at right angles to the river course.

The surface rock zone down to $50 \mathrm{~m}$ in depth from the excavated surface tends to be loose due to a decrease in overburdening and weathering by infiltration of water through these vertical cracks and horizontal bedding planes. On the other hand, the strata deeper than $50 \mathrm{~m}$ from the excavated surface are generally sound, fresh and tight. Sandstone is mainly distributed with intercalation of thin mudstone layers above the weak F7 layer on the higher elevation of the right bank. The fold zone, where cracks might develop because of extreme bending of the strata by orogenic compressive movement, is located at the middle elevation of the right bank. In particular, a high permeability zone of a Lugeon Value (hereinafter 'Lu') of 10 to 20 is widely distributed around the anticlinal axis, as shown in Figs. 2 and 3.

In order to confirm the distribution of cracks and their direction in the fold zone, a borehole camera was sunk in the drilled holes P18 (Block 17) located at the edge of the fold zone and P20 (Block 19) in the center of the anticline. Figure 4 shows geological characteristics such as the number of cracks, crack width and Lu in each stage, in P18 and P20.

As for P18, four (4) high permeability zones were confirmed at 20-25 m, 75-90 m, 95-105 m, and 110$115 \mathrm{~m}$ in depth, respectively through the geological investigation and Lugeon tests. The high permeability zone at 20-25 $\mathrm{m}$ in depth would be related to the weak layer FL-D. Although cracks around the weak layer are both fewer number in and smaller in width, some cracks in the mudstone layer just below the weak layer might show high permeability. The high permeability zone at $75-90 \mathrm{~m}$ is also considered to be related to the weak layer FR-A. The high permeability zones at 95-105 $\mathrm{m}$ and 110-115 $\mathrm{m}$ are located around the boundary between sandstone of $10 \mathrm{~m}$ in thickness and thin mudstone. Although the 
sandstone is impermeable and categorized to be sound and hard rock (as $\mathrm{CH}$-class according to the standard of Central Research Institute of Electric Power Industry, Japan (Central Research Institute of Electric Power Industry 1992), the cracks observed in the drilling core samples are attributed to the stress concentration of the fold movement.

As for P20, relatively high permeable zones are generally seen throughout the hole. These high permeable zones might have originated during crack development in the alternation of sandstone and mudstone that segregated at the stratum boundaries during fold movement.

All cracks observed in holes P18 and P20 are plotted separately on a Schmidt Net as shown in Fig. 5 (Murakami. et al. 2017). The data for P18 are concentrated in the center of the net, indicating that a lot of cracks are of low dip, while the data for P20 are scattered variably in the net, indicating that the cracks for P20 are of variable dip and strike.

\section{Specifications And Current Issues Of The Existing Grouting Methods Conventional Method}

The Conventional Method has been most commonly used for foundation treatment in many hydropower projects in Japan. In the Conventional Method, the water-cement ratio of the grout material is varied from a large number at first for better injection into small cracks, to a smaller number for better injection into larger and wider open cracks. The latest standard for the Conventional Method stipulates a water cement ratio within a range of $10: 1$ to $0.5: 1$, and that check holes be drilled in order to evaluate the performance of grouting works (Kudo et al. 1984). This method is popular and common because it is suitable especially for inhomogeneous geological structures, which are characterized by a variety of geological types and a lot of faults formed by ancient geotechnical activities such as folding and fracture movements. On the other hand, the method has some drawbacks due to its very deliberate and elaborate process:

1) low construction speed, and

2) strict requirements.

Since Japan, which is located on the boundaries of several tectonic plates, has inhomogeneous geological structure compared with Northern Europe, which is located on the Eurasian Plate, the Conventional Method has been applied since the early stage of hydropower development and dam construction in Japan. Records show that the method was applied for the first time to the foundation with fault treatment of the Komaki Dam in 1929. Thereafter, the method has gradually become more sophisticated and standardized based on cumulative experiences.

Firstly, the Design Standards for Dams were published by the Japan Commission on Large Dams in 1957 (Japan Commission on Large Dam 1957). Next, the Design Standards for Dam Foundations were 
published by the Japan Society of Civil Engineers in 1972 (Japan Society of Civil Engineers 1972), which was the first standard for grouting. In 1983, the Technical Guideline for Grouting was published by the former Ministry of Construction (Ministry of Construction River Bureau 1983). And, after a series of experiences and improvements, the updated Technical Guideline with Commentary for Grouting was published by the Ministry of Land, Infrastructure, Transport and Tourism in 2003 (Ministry of Construction River Bureau 2003; lida 2002; Japan Dam Engineering Center 1987). Accordingly, the method has been matured as a technical standard that fits for the inhomogeneous geology in Japan.

Regarding the grouting process, the split spacing method is generally applied where an interpolated layout of holes along the grouting line is applied regardless of the grouting methods as shown in Fig. 6 . The intervals of grouting holes in each step on Site are $24 \mathrm{~m}$ for the pilot hole and $12 \mathrm{~m}$ for the primary hole, accordingly.

\section{GIN Method}

The GIN Method has a set of simple theories represented by total injected volume and grouting pressure to avoid the elaborate work procedure of the Conventional Method. In the GIN Method, a single watercement ratio and stable slurry are used (Kudo et al. 1984; Japan Commission on Large Dam 1957) based on the test results of viscosity and bleeding, so as to inject into even thin cracks, and a single GIN Value is set to plot the below mentioned GIN Curve when applied even in poor geotechnical characteristics. Therefore, the GIN Method helps reduce project costs compared with the Conventional Method because it is not necessary to repeatedly change the grout mix proportion in a grouting procedure. The GIN Method has been adopted for some recent projects in Lao PDR as shown in Table 1. The termination criteria of grouting treatment is defined as a conceptual formula proposed by Dr. Giovanni Lombardi, which indicates the range of grouting pressure and total injected volume (Lombardi 2003). The GIN Value is determined based on the experimental observation and engineering considerations. The upper limits of grouting pressure and total injected volume are proposed as five (5) limit curves, represented by separate GIN Values as shown in Fig. 7 (Lombardi 2003). Known as "GIN Curves", the most suitable curve is selected by trial grouting depending on the characteristics of the geotechnical structure. A sample of the termination criteria of curtain grouting in each step is shown in Fig. 8 (Lombardi 2003).

In the design stage of Nam Ngiep 1, the Conventional Method was planned to be applied to the Site. However, the dam excavation work was so prolonged that the remaining works including the curtain grouting work had to be accelerated. Thus, the GIN Method was applied to recover the time and cost.

\section{Modified GIN Method}

Yoshizu proposed the "Modified GIN Method" as a new grouting method (Yoshizu et al. 2019), which uses a single mix proportion and injected grouting pressure (IGP) principally based on the GIN Curve, but it also uses the water pressure tests. The Modified GIN Method is a practical variation of the GIN Method in that the grouting process may continue even after it reaches the GIN Curve to enhance the efficiency of the grouting work in the inhomogeneous geology. 
The new rule is summarized as shown in Fig. 9 and below.

The grouting process is completed when reaching the Modified GIN Curve with a grouting flow velocity equal to or lower than $0.4 \mathrm{liter} / \mathrm{min} / \mathrm{m}$.

The grouting pressure is maintained until the grouting flow velocity falls below 0.4 liter $/ \mathrm{min} / \mathrm{m}$ even after reaching the GIN Curve.

In the event that the grouting flow velocity is over 0.4 liter $/ \mathrm{min} / \mathrm{m}$ when cumulative grouting volume reaches 600 liter/m, grouting is paused and resumed 3 hours later.

Yoshizu raised the issues to be solved for better application of the method as below (Yoshizu et al. 2019). Figure 10 shows the average Lu and cement take per meter (hereinafter, "unit cement volume" or UCV) in each step on Site. Theoretically, Lu and UCV should decrease as the steps progress. The results of Block 1 (see Fig. 1) show theoretical behavior (see Fig. 10(a)). However, the UCV increases in the final step of Block 2 (see Fig. 10(b)). As shown in Fig. 11, the geology in Block 1 is generally simpler, harder and more impermeable than that in Block 2. It is considered that the main causes of this are that 1) large-scale fractures are newly formed or developed by over-pressurized grouting just before the grouting in the final step, and/or 2) Block 2 has an extremely steep topography on the surface, which is supposedly derived from toppling phenomenon. As a result, the vertical cracks perpendicular to the dam axis in Block 2 might be difficult to grout from the grouting holes that were vertically drilled parallel to the vertical cracks, and hence not improved in the earlier steps. According to Figs. 10(c) and 10(d), it is found that the UCV of Blocks 13 and 14 is similarly larger in the final step than in the early steps as in Block 2.

In order to further pursue the reason, parameters such as Critical Grouting Pressure (CGP) and UCV are analyzed in each block. The average CGP and UCV of the sandstone, mudstone and weak layers in Blocks 12, 13, 14 and 15 are shown in Fig. 12. It is assumed that there are few cracks in Blocks 12 to 15 because they are located in the riverbed where there are few of the large-scale fractures seen in Block 2. However, comparing the respective values shown in Fig. 12, the UCV in the weak layers is larger than that in the sandstone and mudstone though the CGP in the weak layers is smaller than that in sandstone and mudstone. The reason for this is assumed that the weak layers are so sensitively affected by the geotechnical actions that the fractures might have easily induced.

To pursue the possible reason of the fractures inducement in the weak layers, the step-by-step transition of the Lu and the UCV are as follows. The degree of grout improvement in weak layers by the Modified GIN Method is investigated by Progress Management Method ("PMM") for grouting. As shown in Fig. 13, the horizontal axis represents the difference in $\mathrm{Lu}(\triangle \mathrm{Lu})$ and the vertical axis represents the difference in UCV ( $\triangle U C V)$ at the transition of each step. For example, when Lu decreases from 40 to 30 and UCV decreases from 300 to 200 through a step, $(\Delta L u ;-10, \Delta U C V ;=-100)$ is plotted. That is, the chart of PMM indicates that the grouting is proceeding appropriately when the data concentrates in the third quadrant and moves to the center as the step progresses. Figure 14 shows the transition of Lu and UCV in each step determined by PMM for Blocks 12 to 15 that had weak layers that were grouted by the Modified GIN 
Method. Figure 14(a) indicates that Lu and UCV did not improve well with tertiary hole grouting because the data are scattered in all of the quadrants. Figure 14(b) indicates that both Lu and UCV show some improvement by quarterly hole grouting because the data are concentrated in the 3rd quadrant. Figure 14(c) indicates that Lu and UCV get larger in the final step because the data moves to the 1st quadrant again. This means that cracks might develop due to over-pressurized grouting.

Next, the CGP are analyzed in detail. Too high of an IGP may cause harmful damage to the dam foundation, therefore the IGP should not exceed the CGP too much. However, it is common practice to set IGP slightly higher than the CGP as shown by the green line in Fig. 15, so as not to leave any voids in the cracks in the dam foundation. It should be noted that the Modified GIN Method has a weak point in that the IGP might in certain cases not reach the CGP, as occurred in Blocks 1, 2, 13 and 14 as shown in the red area in Fig. 15.

Originally, the CGP was simply supposed in accordance with the depth of the grouting holes. However, as shown in Fig. 16, its variation is too large compared with the highest envelop of the CGP against depth $(H)$. Thus, it was concluded that the CGP should be correctly determined by conducting water pressure tests stage by stage. It is considered that the injection may have been paused or terminated before the void was sufficiently filled in the intermediate step due to a relatively lower IGP than CGP in some stages. It is also considered that the injection volume may unhelpfully have increased in the final step due to cracks developing as a result of IGP becoming much higher than CGP as shown in the blue area in Fig. 15. As shown in Fig. 15, IGP was significantly higher than CGP in 110 stages, equivalent to 65\%, where the injection volume may impractically have increased in the final step due to cracks developing because of the excessive IGP. To solve the issue, a new method should have been developed whereby a proper IGP is set based on the CGP obtained from the water pressure test in each stage. Applicable conditions of this new method and the GIN Method are also proposed depending on the geological situation. Therefore, by carefully regulating the IGP according to geotechnical conditions, it is possible to improve permeability of the dam foundation effectively.

\section{Development Of Hybrid Method}

\section{Planning and Verification}

The new method the authors have developed is totally different from the Modified GIN Method. The grouting work is managed only by grouting pressure, not by correlations between grouting pressure and grouting volume. The design pressure is set based on the CGP obtained from the water pressure test in each stage. Since the new method shown in Fig. 17 has characteristics of both the Conventional and the GIN Method, it is named the "Hybrid Method". In the Hybrid Method, permeability and CGP are confirmed in advance through the water pressure tests at each stage in the same manner as the Conventional Method. A single mix proportion is adopted in the same manner as the GIN Method. The grouting specifications of the Hybrid Method are shown in Fig. 17. A water-cement ratio (W/C) of 1.5 is applied as a single mix proportion, which has been optimized by the preliminary grouting test (Yoshizu et al. 2019). 
In the case of a zero IGP, open cracks are considered to be distributed, and thus surplus cement volume is required. Therefore, the mix proportion is immediately changed to a W/C of 0.8 , which has higher viscosity.

\section{Technical Applicability}

A ratio of incompatibility of the target $L u\left(P_{L u}\right)$ is adopted to assess the effect of curtain grouting by Hybrid Method applied to Blocks 18 and 22 located in the fold zone (see Fig. 1). As shown in the following formula, it is defined as the ratio of the number of stages which do not meet the target Lu against the total number of stages. It is difficult to achieve a sufficient improvement effect of grouting on an inhomogeneous geotechnical structure using the GIN Method. To illustrate this, the transition of grout volume and Lu by the order of the steps of the Modified GIN Method is shown in Fig. 10.

The Hybrid Method was applied to the fold zone (Blocks 18-22) which is the most inhomogeneous geotechnical structure on Site, as this is where alternate sandstone and mudstone with the weak layer FRA intercalated are distributed, as shown in Fig. 1. In addition, the fold zone bends extremely under fold movement resulting in the development of cracks according to the Schmidt net plots at P20 as shown in Fig. 5.

On the other hand, the Hybrid Method verifies the effectiveness of grouting as follows. Figure 18 shows PLu as explained above for Blocks 18-22. It was shown that all the blocks in Blocks 18-22 achieved a PLu lower than the target value of $15 \%$ for the ratio of the number of stages that fail to satisfy the target Lu of 2.0 in the final step. Figure 19 shows the average Lu and UCV in each step of Blocks 18-22. As grouting sequences progress using the Hybrid Method, the average Lu and UCV decrease so consistently, that these results would almost seem theoretical when compared to the Modified GIN Method. Also, Fig. 20 shows that the correlation between the IGP at the vertical axis and the CGP at the horizontal axis seems to be quite appropriate. If the IGP is much higher than the CGP, it is likely to fracture the foundation rock due to surplus grouting pressure. On the contrary, if the IGP is much lower than the CGP, it is not likely to improve sufficiently by grouting. The graph indicates that the IGP is slightly higher than the CGP. An average UCV of $533.5 \mathrm{~kg} / \mathrm{m}$ for all Blocks 18-22 using the Hybrid Method is smaller than that of $627.6 \mathrm{~kg} / \mathrm{m}$ at Block 14 using the Modified GIN Method. Based on the above, it has been concluded that the Hybrid Method is technically as well as cost-wise superior to the Modified GIN Method for the inhomogeneous geotechnical structure under the same criteria of target Lu of less than 2.

\section{Economical Applicability}

The previous section demonstrated the technical superiority of the Hybrid Method over the Modified GIN Method in the context of the inhomogeneous geotechnical structure. This section of the paper demonstrates the economical superiority of the Hybrid Method, vis-a-vis the Conventional and GIN Methods (Dou et al. 2020). Blocks 1, 2, 12, 13, 14 and 15 were selected for the comparative study among the methods; all these methods were applied for the preliminary grouting tests and, as a result, all necessary data for the comparative study is available. As mentioned in the "Site Geology" section, conglomerate is mainly distributed in Blocks 1 and 2 on the higher elevation of the left bank, and the 
weak layers FL-D and FR-A are located in Blocks 12, 13, 14 and 15 in the riverbed. Both simple and inhomogeneous geological conditions with conglomerate or weak layers were assumed in the same dimensions (50 $\mathrm{m}$ deep) below. The target Lu should be the same among the GIN, Conventional and Hybrid Methods as shown in Table 2. In the simple geological structure with pure sandstone and/or mudstone, grouting could be terminated by the tertiary hole in all methods based on Site records. An image of a grouting layout in the simple geological condition is shown in Fig. 21.

- The grouting can be terminated by the tertiary hole in all stages and methods based on Site records.

- Unit prices in each work scope are set referring to the construction contract of the Nam Ngiep 1 Project.

- The unit price of admixture per $\mathrm{kg}$ is supposed as 1 and the other unit prices are proportionally estimated.

Table 3 shows the result of the study for the simple geological condition. In the case that the cost using the GIN Method is 1.0, the cost using the Hybrid Method is 1.16 and the cost using the Conventional Method is 1.53 because the target Lu can be achieved by high-pressured grouting in a short time.

Next, the inhomogeneous geological conditions for the comparative study are mentioned below. In the inhomogeneous geological structure with conglomerate and weak layers on Site, additional grouting more than a quaternary hole is required for the GIN Method based on Site records. An image of grouting under the inhomogeneous geological conditions is shown in Fig. 22.

- In case of using the GIN Method, additional drilling is required for inhomogeneous geology based on Site records because the target Lu cannot be achieved by the tertiary hole.

- Unit prices in each work scope are set referring to the construction contract of the Nam Ngiep 1 Project.

- The unit price of admixture per $\mathrm{kg}$ is supposed as 1 and the other unit prices are proportionally estimated.

Table 4 shows the study results in the inhomogeneous geological conditions with conglomerate or weak layers. In the case that the cost using the GIN Method is 1.0, the cost using the Hybrid Method is 0.85 because additional drilling cost is not needed.

The results of the economical comparative study are shown in Fig. 23. The estimated cost of the GIN Method for the simple geological condition is regarded as 1.0 (100\%). Generally, the GIN Method is considered to be preferable in cases of simple geological conditions without significant cracks, while the Hybrid Method is considered to be preferable in cases of inhomogeneous geological conditions with weak layers and fold zone.

\section{Conclusions}


The Hybrid Method has been newly developed for the inhomogeneous geology of weak layers, toppling and fold zone in the Nam Ngiep 1 Hydropower Project. The method is literally "hybrid" as it garners the economical superiority of the GIN Method in that it enables use of a single mix proportion, and the technical superiority of the Conventional Method in that the individual design pressure in each stage is based on the CGP obtained from water pressure tests. The followings are the conclusions in this study.

- The GIN Method is the economically preferred method for simple geological site conditions.

- However, in situations with inhomogeneous geological conditions with weak layers, the Hybrid Method is economically superior to the GIN/Modified GIN Method under the same technical criteria.

- CGP should be correctly determined by conducting water pressure tests for the inhomogeneous geotechnical structures.

- It is believed that further simplification of the water pressure test procedure will make the Hybrid Method more economically competitive.

- An applicational boundary between the Modified GIN and the Hybrid Method could be specified by the geological conditions with and without weak layers. Further studies are recommended to specify the boundaries between the GIN Method and the Modified GIN Method, and between the Hybrid Method and the Conventional Method.

The proposed categories of grouting methods are summarized in Fig. 24. As mentioned in this paper, as the geological features vary from simple to inhomogeneous, the applicable grouting method generally transitions from the GIN Method to the Conventional Method (left to right in the figure). In this study, the boundary between the Modified GIN and the Hybrid Method could be specified as shown by the red line in this figure. Unfortunately, no data could be obtained for the use of the Modified GIN Method in the stages with conglomerate. It is expected to specify the boundaries between the GIN Method and the Modified GIN Method, and between the Hybrid Method and the Conventional Method. Further studies are recommended to introduce a rigorous system for specifying the most appropriate grouting method for the clearly defined category of the geological condition. For that purpose, preliminary grouting for a comparative study of the grouting methods in the other dam construction sites is recommended to accumulate such data.

It is expected that the number of dam constructions with inhomogeneous geological conditions in Southeast Asia will increase going forward, and it is anticipated that further sophistication of the Hybrid Method will improve its economical attractiveness. This, in turn, will have a positive impact on the economic feasibility and the construction period of the projects to which it is applied. It is desirable that a simpler and quicker method than the elaborated water pressure tests be developed soon.

\section{Declarations}

- Funding: Not applicable 
- Conflicts of interest/Competing interests: Not applicable

- Availability of data and material: Not applicable

- Code availability: Not applicable

- Authors' contributions: Not applicable

\section{ACKNOWLEDGMENTS}

The authors would like to extend their greatest appreciation to Dr. Kiyoshi Kishida, Professor of Urban Management Systems, Kyoto University for providing extraordinarily tolerant and supportive technical advice, and to Mr. Ernst, freelance contract specialist for his insightful comments and suggestions.

\section{References}

1. Central Research Institute of Electric Power Industry (1992) Rock Class Classification. Engineering Geology:79-80. (in Japanese)

2. Committee on Rock Mechanics - Japan Society of Civil Engineers (1972) Foundation Grouting of Concrete Dams. Japan Society of Civil Engineers:7. (in Japanese)

3. Dou J., Zhang G., Zhou M., Wang Z., Gyatso N., Jiang M., Safari P. \& Liu J. (2020) Curtain grouting experiment in a dam foundation: case study with the main focus on the Lugeon and grout take tests. Bulletin of Engineering Geology and the Environment Vol.79:4527-4547.

4. lida R. (2002) Grouting for Dam Foundation. Japan Dam Engineering Center:1-387. (in Japanese)

5. Japan Commission on Large Dams (1957) Design Criteria of Dam. Large Dams:55. (in Japanese)

6. Japan Dam Engineering Center (1987) Construction of Multi-Purpose Dam (Design Edition, Part II). Japan Construction Training Center:43-75. (in Japanese)

7. Kudo H., Momikura Y., and Nishijima T. (1984) Basic Knowledge of Grouting - No.2. Journal of the Agricultural Engineering Society Vol.52 1:61-66. (in Japanese)

8. Li J., Xu L., and Xu M. (2017) Optimization Study on Grouting Method Based on the Grouting Intensity Number. International Journal of Simulation Systems, Science and Technology Vol.17 1:35.1-35.3.

9. Lombardi G., Deere D. (1993) Grouting Design and Control Using the GIN Principle. Water Power \& Dam Construction:15-22.

10. Lombardi G. (1996) Selecting the Grouting Intensity. Hydropower and Dams 4:62-66.

11. Lombardi G (2003) Grouting of Rock Masses, $3^{\text {rd }}$ International Conference on Grouting and Grout Treatment:1-43.

12. Ministry of Construction River Bureau (1983) Technical Standards of Grouting. Japan Institute of Country-ology and Engineering:27. (in Japanese) 
13. Ministry of Land, Infrastructure, Transport and Tourism (2003) Technical Standards of Grouting Revised. Japan Institute of Country-ology and Engineering:87. (in Japanese)

14. Murakami Y., and Tabuchi T. (2017) Study on Excavation of Dam Foundation and Slope Stability The Nam Ngiep 1 Hydropower Project, Lao PDR. Electric Power Civil Engineering 387:51-54. (in Japanese)

15. Shahzad I. M., Afridi Z. N., Jadoon A. T., and Ahmad S. (2017) A Case Study of Trial Grouting using Grouting Intensity Number (GIN) and Conventional Method at Tarbela $4^{\text {th }}$ Foundation Tarbela Dam. Journal of Geotechnical and Transportation Engineering Vol.3 (Issue 2):47-51.

16. Tabuchi T., Kawata T., Ogawa M., and Murakami Y. (2017) Consolidation Grouting for Dam Foundation - The Nam Ngiep 1 Hydropower Project, Lao PDR. Electric Power Civil Engineering 392:83-87. (in Japanese)

17. Tsutsui S., Murakami Y., Kawata T., Tanaka R., Kubo K., and Cockcroft E. M. J. (2021) Commencement of Operation of Sustainable Nam Ngiep 1 Hydropower in Lao PDR. Hydropower Asia 2020:12.

18. Weaver D. K., and Bruce A. D. (1991) Dam Foundation Grouting. American Society of Civil Engineering:473.

19. Weaver D. K., and Bruce A. D. (2007) Dam Foundation Grouting, Revised and Expanded Edition. American Society of Civil Engineers:504.

20. Yoshizu Y., Fujii T., Nakamura K., and Kawata T. (2019) Proposal and Verification of Applicability of Modified GIN Method for Curtain Grouting - The Nam Ngiep 1 Hydropower Project, Lao PDR. Electric Power Civil Engineering 402:21-28. (in Japanese)

21. Yoshizu Y., Iseki K., Iseki H., Nakajima S., \& Kishida K. (2020) Image Analysis and Evaluation on Grouting Conditions employed Modified GIN Grouting Method through $\mu$-Focus X-ray CT. Journal of Japan Society of Civil Engineering Vol.76:394-404. (in Japanese)

\section{Tables}

Table 1. Lao PDR Project using GIN Method

\begin{tabular}{cccc}
\hline \hline Project Name & Xayaburi & Theun-Hinboun Exp. & Nam Ngiep 1 \\
\hline Dam Type & CVC & RCC & RCC \\
Dam Height & $33 \mathrm{~m}$ & $72 \mathrm{~m}$ & $167 \mathrm{~m}$ \\
\hline \hline \multicolumn{4}{c}{ Table 2. Target Lu } \\
\hline Depth for Foundation Treatment & Target Lu & PLu in the Final \\
\hline \\
\hline
\end{tabular}


Table 3. Result of Economical Comparative Study for Simple Geological Condition

\begin{tabular}{ccccccccc}
\hline \hline Work Item & Unit & Unit Price & \multicolumn{3}{c}{ Qty. } & \multicolumn{3}{c}{ Amount } \\
(Primary to Tertiary Hole) & & & GIN & Hyb. & Conv. & GIN & Hyb. & Conv. \\
\hline Drilling (5m/stage) & $\mathrm{m}$ & 15 & 5 & 5 & 5 & 75 & 75 & 75 \\
Water pressure test & times & 25 & 0 & 1 & 1 & 0 & 25 & 75 \\
Injection time & hour & 25 & 0.5 & 1 & 3 & 12.5 & 25 & 75 \\
Cement take & ton & 37.5 & 1 & 0.5 & 0.5 & 37.5 & 18.75 & 18.75 \\
Admixture & $\mathrm{kg}$ & 1 & 2.5 & 3.75 & 1.25 & 2.5 & 3.75 & 1.25 \\
Total & & & & & & 127.5 & 147.5 & 195 \\
\hline per meter & $\mathrm{m}$ & & & & & 1.70 & 1.97 & 2.60 \\
per target area (350m) & & & & & & 595.0 & 688.3 & 910.0 \\
GIN equal to 1.0 & & & & & & 1.00 & 1.16 & 1.53 \\
\hline \hline
\end{tabular}

Table 4. Result of Economical Comparative Study for Inhomogeneous Geological Condition

\begin{tabular}{|c|c|c|c|c|c|c|c|c|c|c|}
\hline $\begin{array}{l}\text { Grouting } \\
\text { progress }\end{array}$ & $\begin{array}{l}\text { Assumed } \\
\text { Qty. }\end{array}$ & Work Item & Unit & Unit Price & GIN & $\begin{array}{l}\text { Qty. } \\
\text { Hyb. }\end{array}$ & Conv. & GIN & $\begin{array}{l}\text { Amount } \\
\text { Hyb. }\end{array}$ & Conv. \\
\hline \multirow[t]{5}{*}{$\begin{array}{l}\text { Primary to } \\
\text { Tertiary }\end{array}$} & $\begin{array}{l}50 \mathrm{~m} \times 7 \\
\text { stages }\end{array}$ & $\begin{array}{c}\text { Drilling } \\
\text { (5m/stage) }\end{array}$ & $\mathrm{m}$ & 15 & 350 & 350 & 350 & 5,250 & 5,250 & 5,250 \\
\hline & & $\begin{array}{l}\text { Water pressure } \\
\text { test }\end{array}$ & times & 25 & 0 & 70 & 70 & 0 & 1,750 & 1,750 \\
\hline & & Injection time & hour & 25 & 35 & 70 & 210 & 875 & 1,750 & 5,250 \\
\hline & & Cement take & ton & 37.5 & 70 & 35 & 35 & 2,625 & $1,312.5$ & $1,312.5$ \\
\hline & & Admixture & $\mathrm{kg}$ & 1 & 175 & 262.5 & 87.5 & 175 & 262.5 & 87.5 \\
\hline \multirow[t]{5}{*}{ Quaternary } & $\begin{array}{l}30 \mathrm{~m} \times 5 \\
\text { stages }\end{array}$ & $\begin{array}{c}\text { Drilling } \\
(5 \mathrm{~m} / \mathrm{stage})\end{array}$ & $\mathrm{m}$ & 15 & 150 & 150 & 150 & 2,250 & 2,250 & 2,250 \\
\hline & & $\begin{array}{l}\text { Water pressure } \\
\text { test }\end{array}$ & times & 25 & 0 & 30 & 30 & 0 & 750 & 750 \\
\hline & & Injection time & hour & 25 & 15 & 30 & 90 & 375 & 750 & 2,250 \\
\hline & & Cement take & ton & 37.5 & 30 & 15 & 15 & 1,125 & 562.5 & 562.5 \\
\hline & & Admixture & $\mathrm{kg}$ & 1 & 75 & 112.5 & 37.5 & 75 & 112.5 & 37.5 \\
\hline \multirow[t]{5}{*}{ Quinary } & $\begin{array}{l}30 \mathrm{~m} \times 4 \\
\text { stages }\end{array}$ & $\begin{array}{c}\text { Drilling } \\
(5 \mathrm{~m} / \mathrm{stage})\end{array}$ & $\mathrm{m}$ & 15 & 120 & 0 & 0 & 1,800 & 0 & 0 \\
\hline & & $\begin{array}{l}\text { Water pressure } \\
\text { test }\end{array}$ & times & 25 & 0 & 0 & 0 & 0 & 0 & 0 \\
\hline & & Injection time & hour & 25 & 12 & 0 & 0 & 300 & 0 & 0 \\
\hline & & Cement take & ton & 37.5 & 24 & 0 & 0 & 900 & 0 & 0 \\
\hline & & Admixture & $\mathrm{kg}$ & 1 & 60 & 0 & 0 & 60 & 0 & 0 \\
\hline \multirow[t]{5}{*}{ Senary } & $\begin{array}{l}30 \mathrm{~m} \times 2 \\
\text { stages }\end{array}$ & $\begin{array}{c}\text { Drilling } \\
(5 \mathrm{~m} / \mathrm{stage})\end{array}$ & $\mathrm{m}$ & 15 & 60 & 0 & 0 & 900 & 0 & 0 \\
\hline & & $\begin{array}{l}\text { Water pressure } \\
\text { test }\end{array}$ & times & 25 & 0 & 0 & 0 & 0 & 0 & 0 \\
\hline & & Injection time & hour & 25 & 6 & 0 & 0 & 150 & 0 & 0 \\
\hline & & Cement take & ton & 37.5 & 12 & 0 & 0 & 450 & 0 & 0 \\
\hline & & Admixture & $\mathrm{kg}$ & 1 & 30 & 0 & 0 & 30 & 0 & 0 \\
\hline Total & & & & & & & & 17,340 & 14,750 & 19,500 \\
\hline $\begin{array}{c}\text { GIN equal to } \\
1.0\end{array}$ & & & & & & & & 1.00 & 0.85 & 1.12 \\
\hline
\end{tabular}




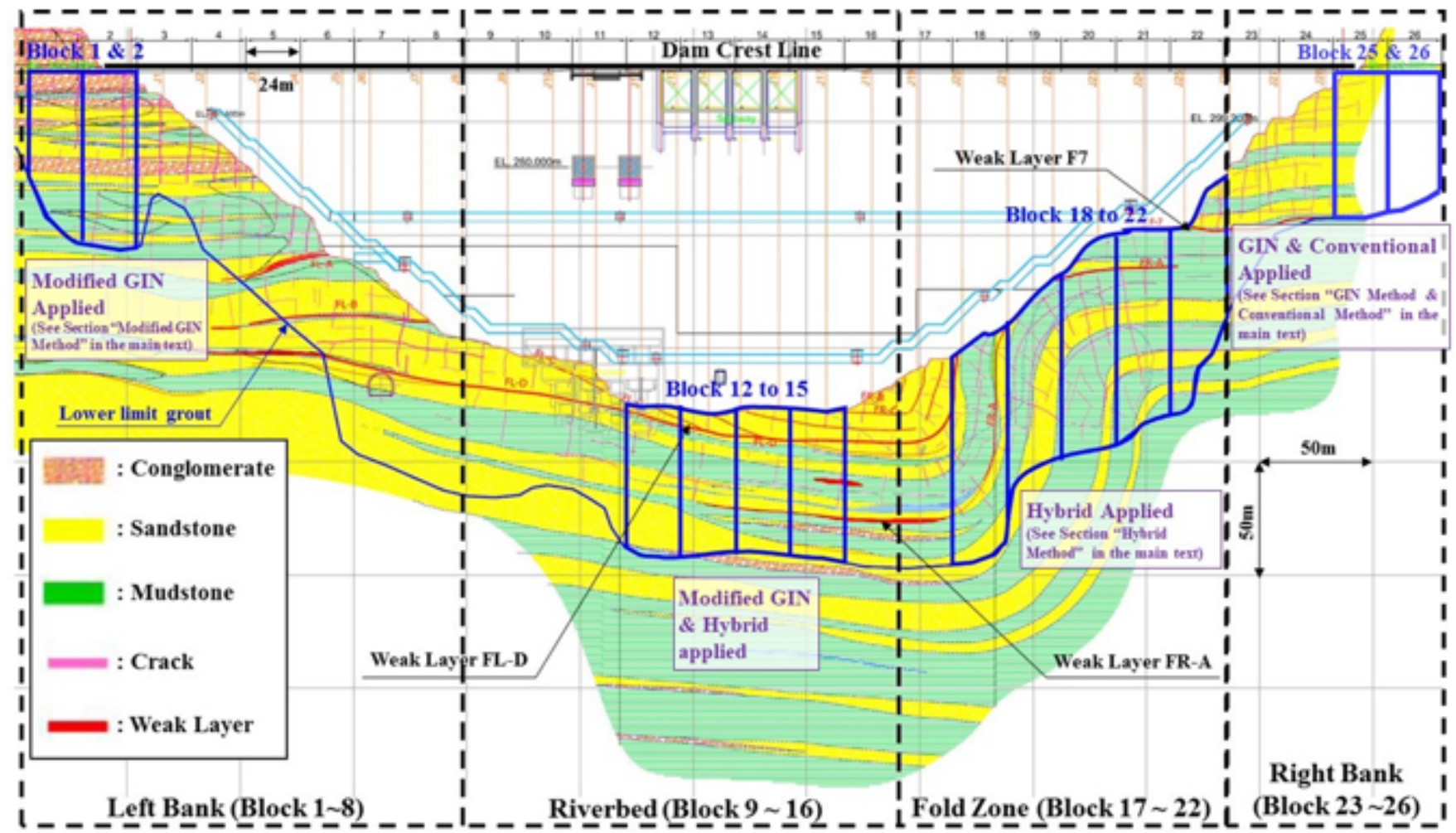

Figure 1

Geological Map with Cracks and Weak Layers (Upstream View)

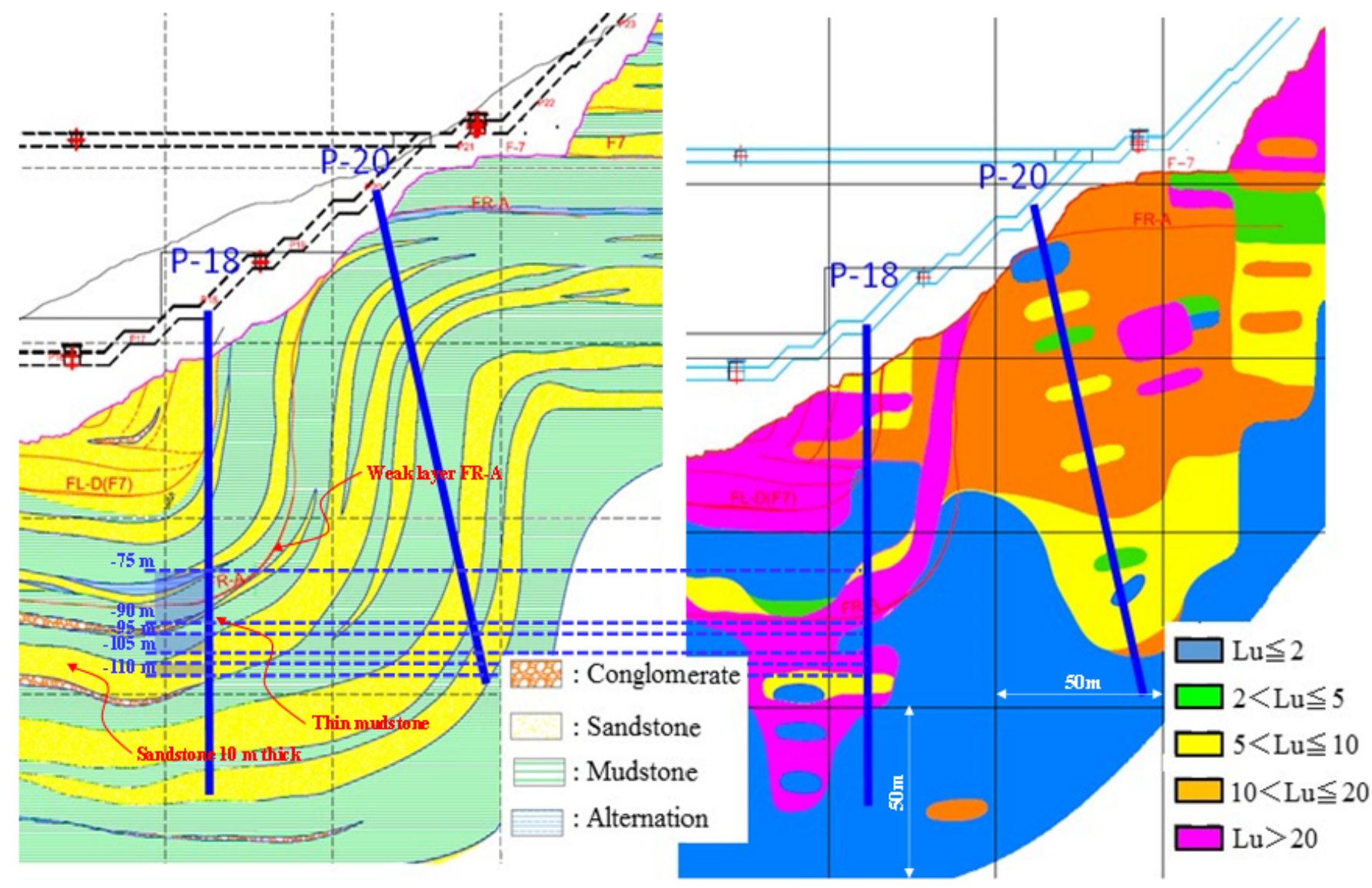


Figure 2

Geological Map around Fold Zone

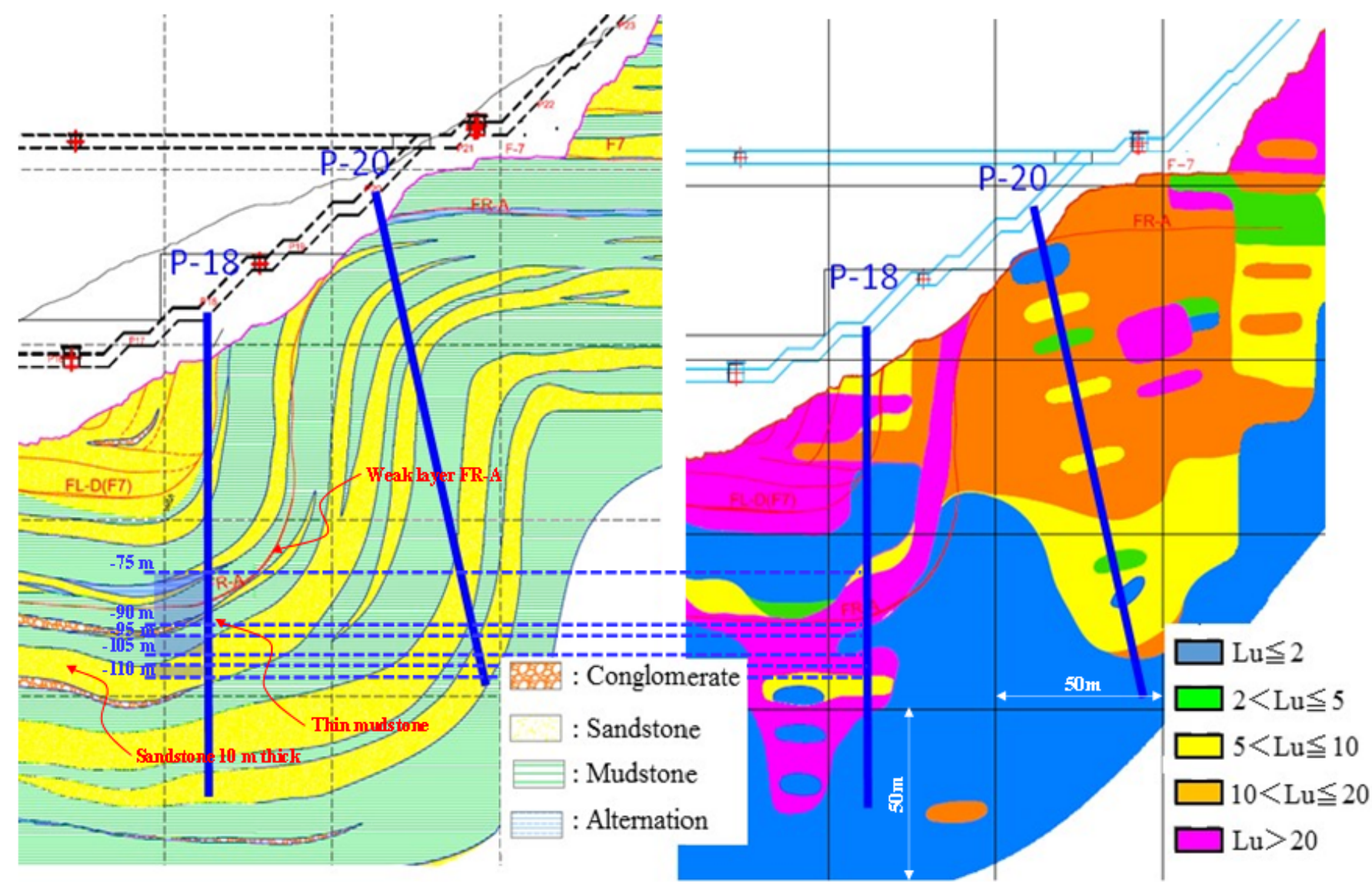

Figure 3

Lugeon Map around Fold Zone 

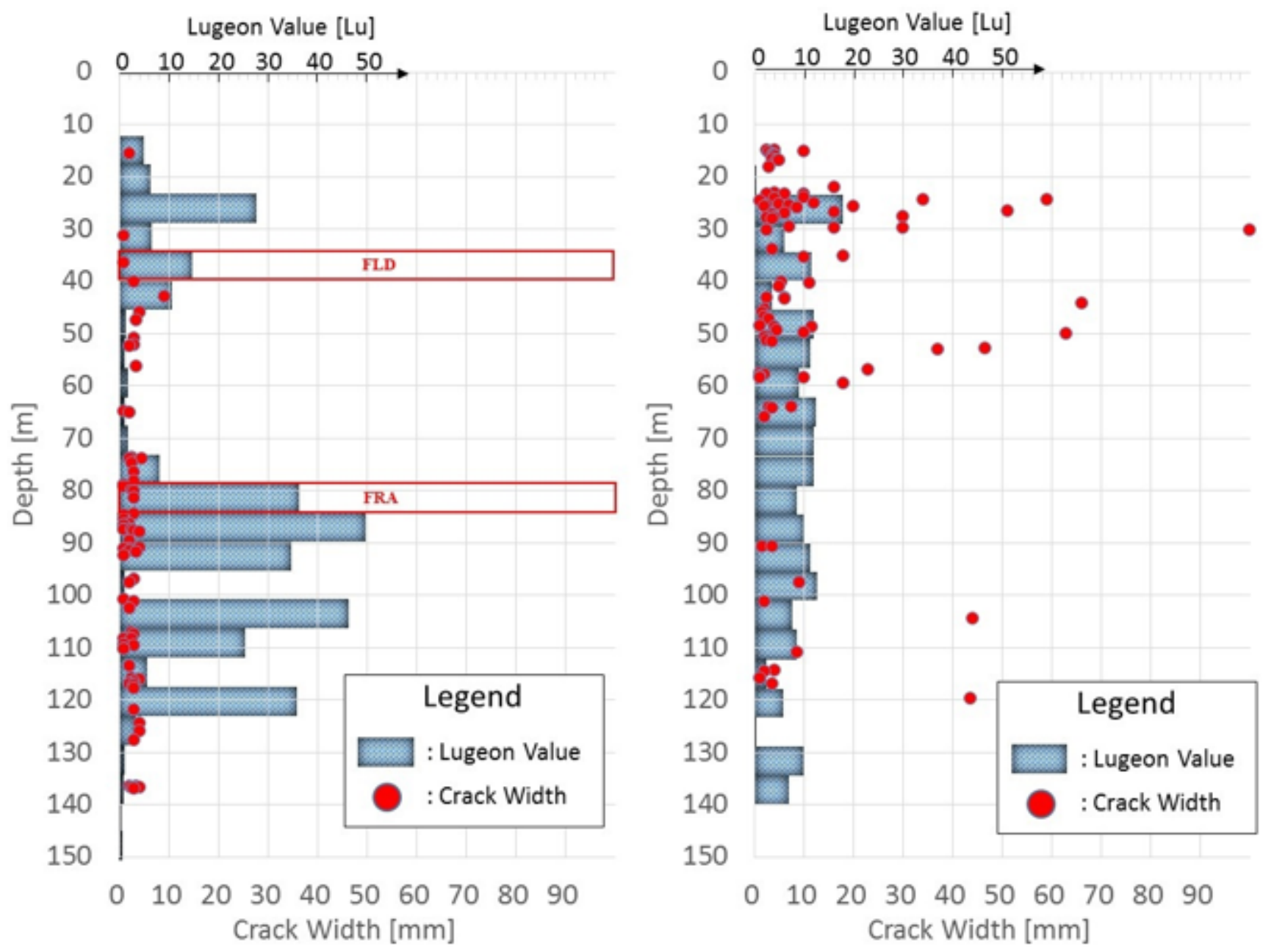

\section{Figure 4}

Crack Width and Lugeon Value for P18 and P20
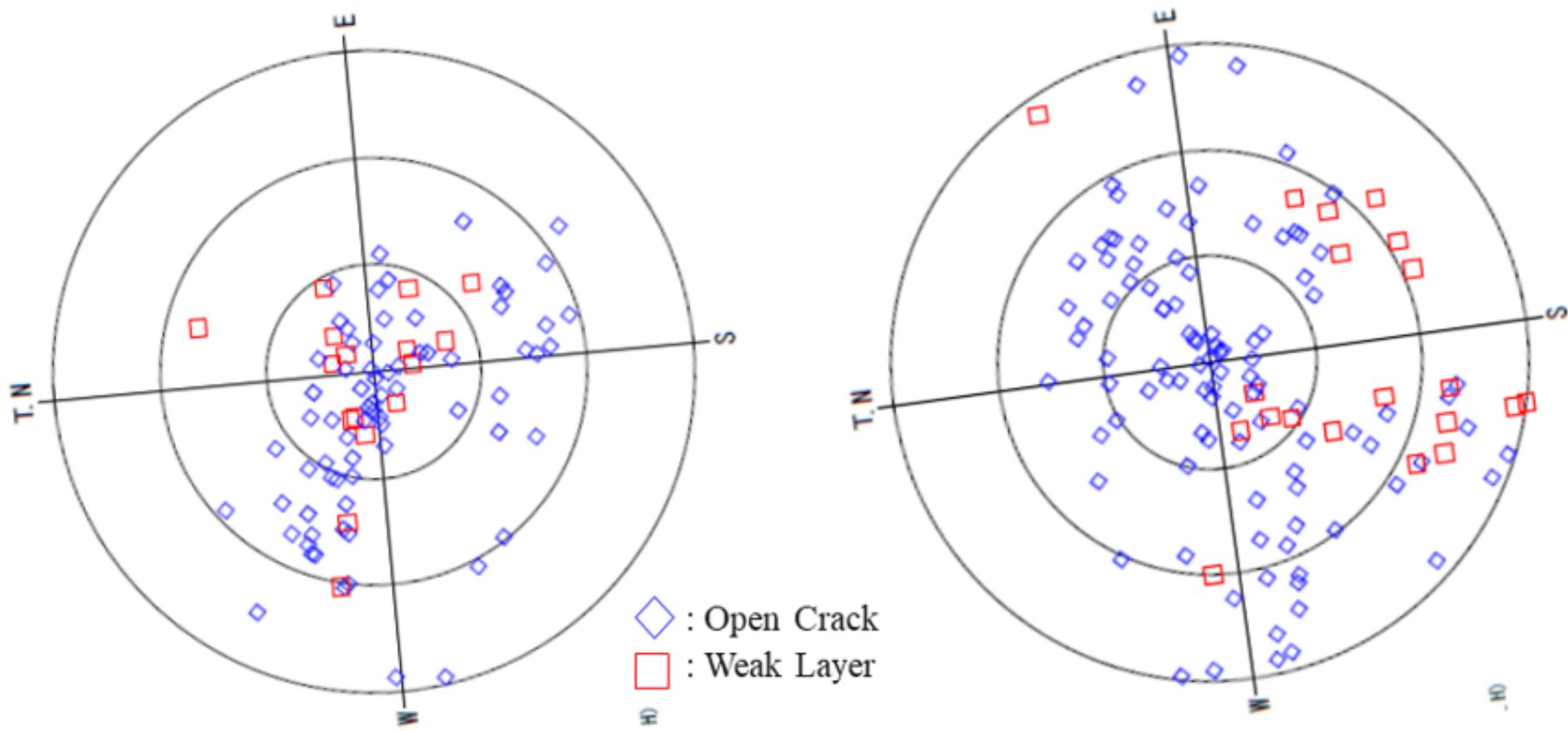
Figure 5

Schmidt Net Plots for P18 and P20

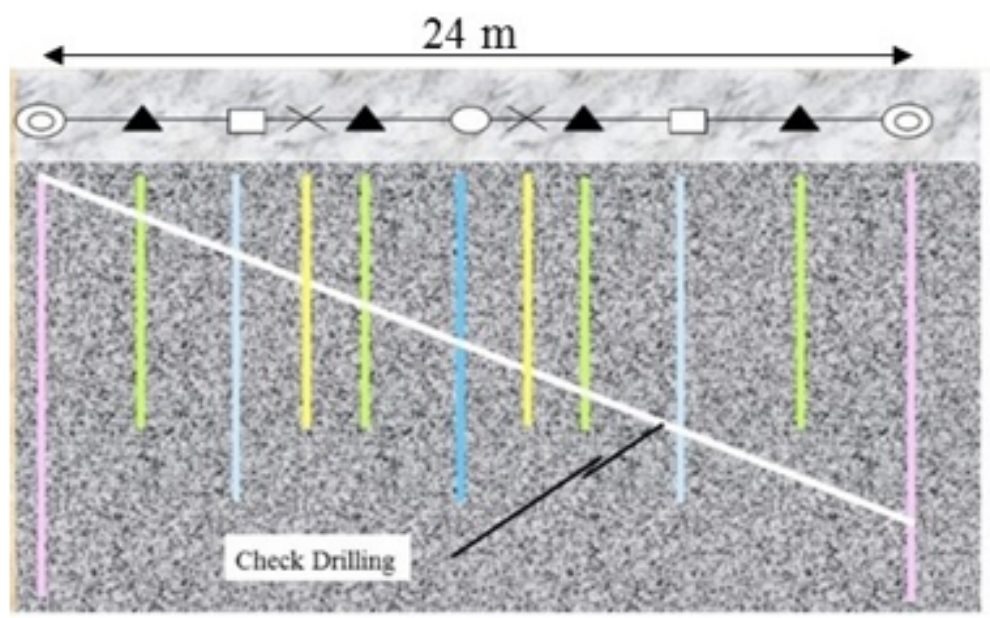

$$
\begin{aligned}
& \text { (0) Pilot } \\
& 0 \frac{\text { Primary }}{\text { Secondary }} \\
& \text { Tertiary } \\
& \text { Quaternary }
\end{aligned}
$$

Figure 6

Typical Curtain Grouting Pattern by Split Spacing Method

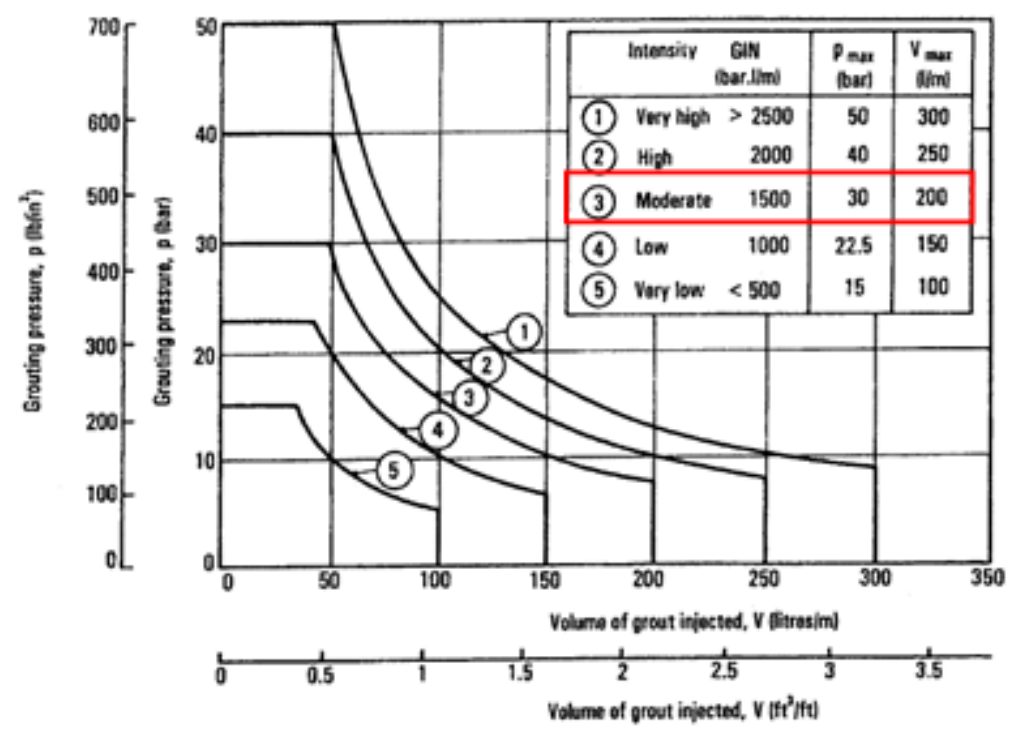

Figure 7

Typical GIN Curve 


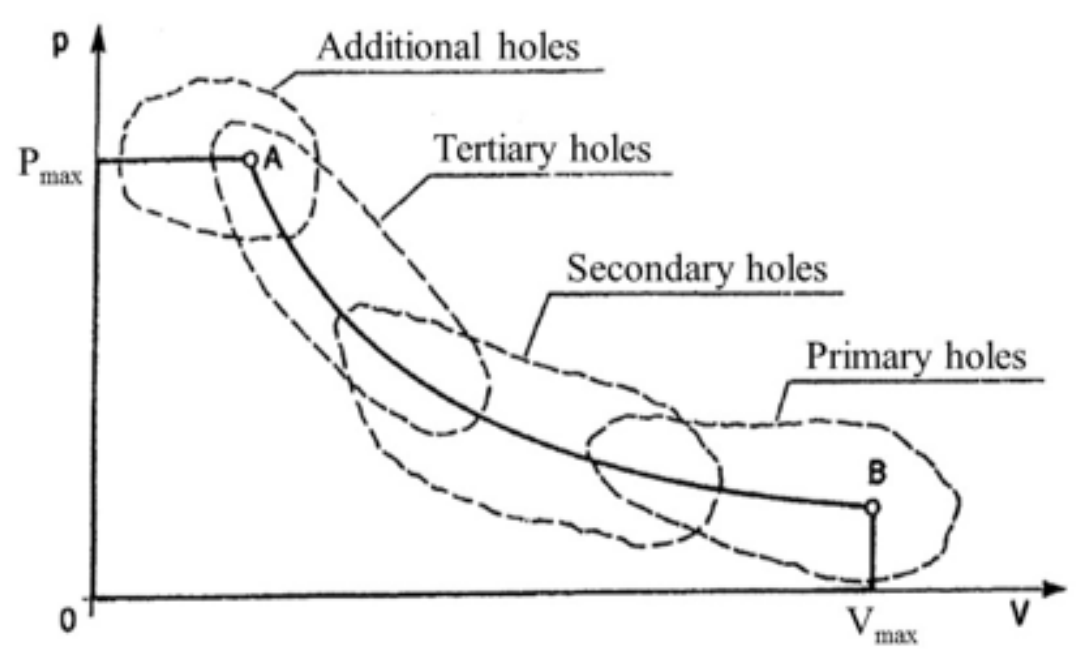

Figure 8

Theoretical Termination Range in Each Step

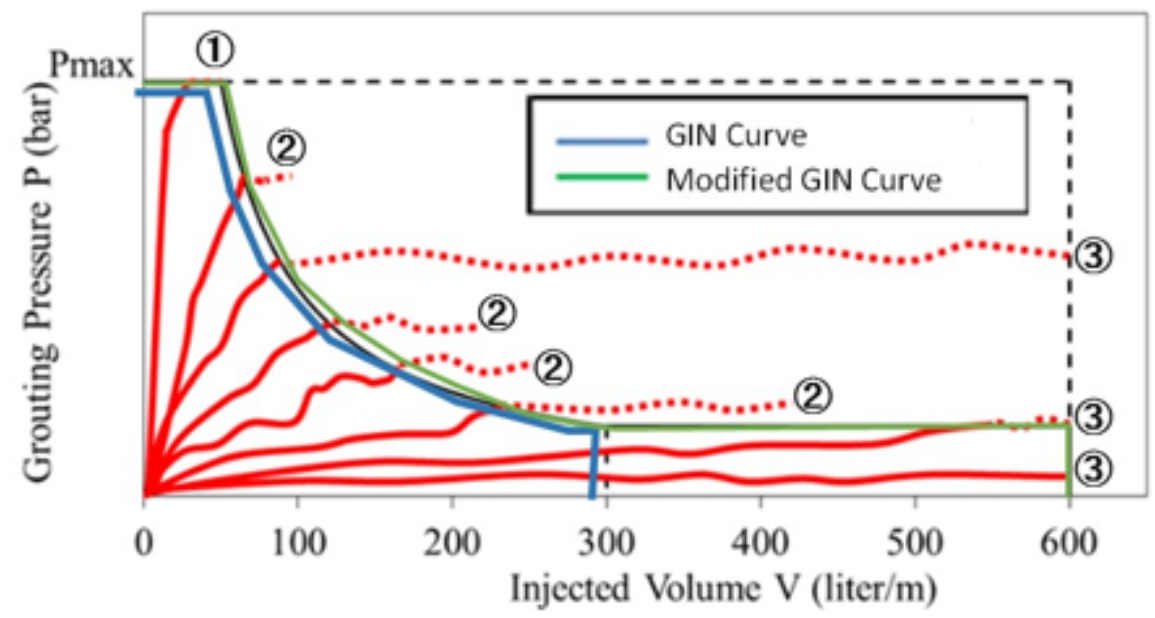

Figure 9

Termination Criteria of Grout Injection $\otimes T h e$ grouting process is completed when reaching the Modified GIN Curve with a grouting flow velocity equal to or lower than $0.4 \mathrm{liter} / \mathrm{min} / \mathrm{m}$. $\otimes T$ The grouting pressure is maintained until the grouting flow velocity falls below $0.4 \mathrm{liter} / \mathrm{min} / \mathrm{m}$ even after reaching the GIN Curve. Qln the event that the grouting flow velocity is over $0.4 \mathrm{liter} / \mathrm{min} / \mathrm{m}$ when cumulative grouting volume reaches $600 \mathrm{liter} / \mathrm{m}$, grouting is paused and resumed 3 hours later. 


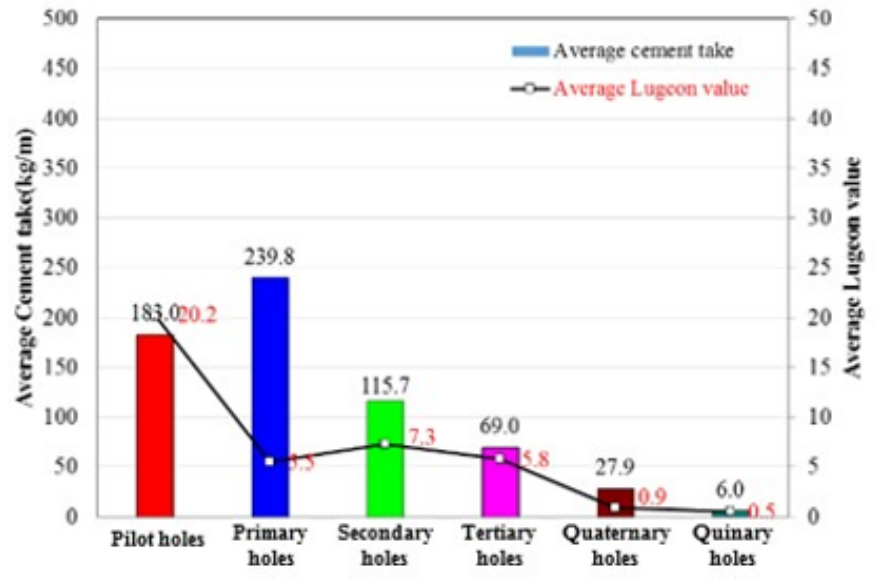

Fig. 10(a) Block 1

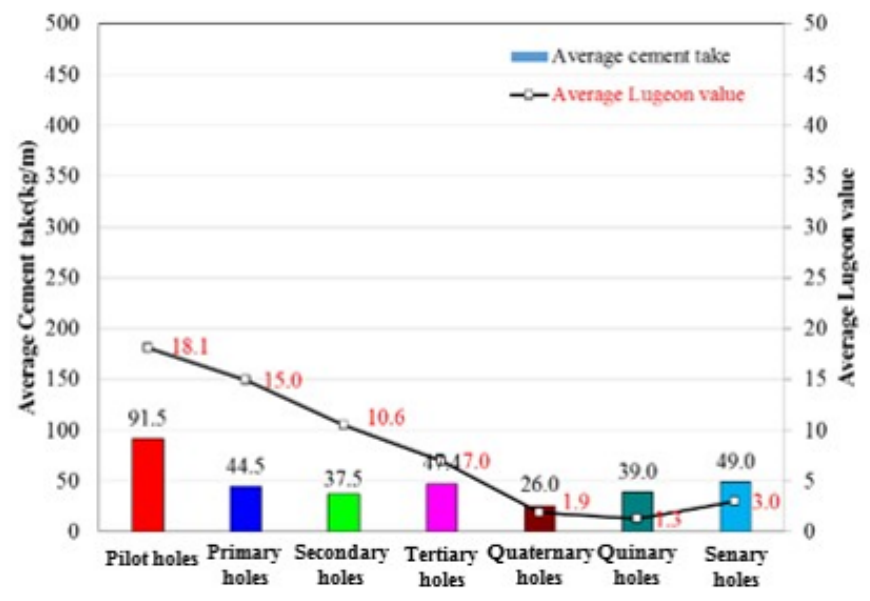

Fig. 10(c) Block 13

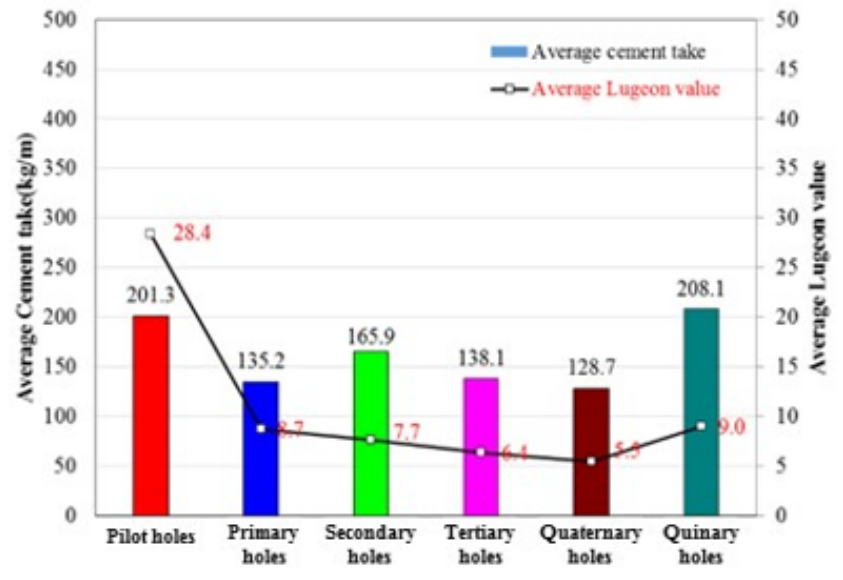

Fig. 10(b) Block 2

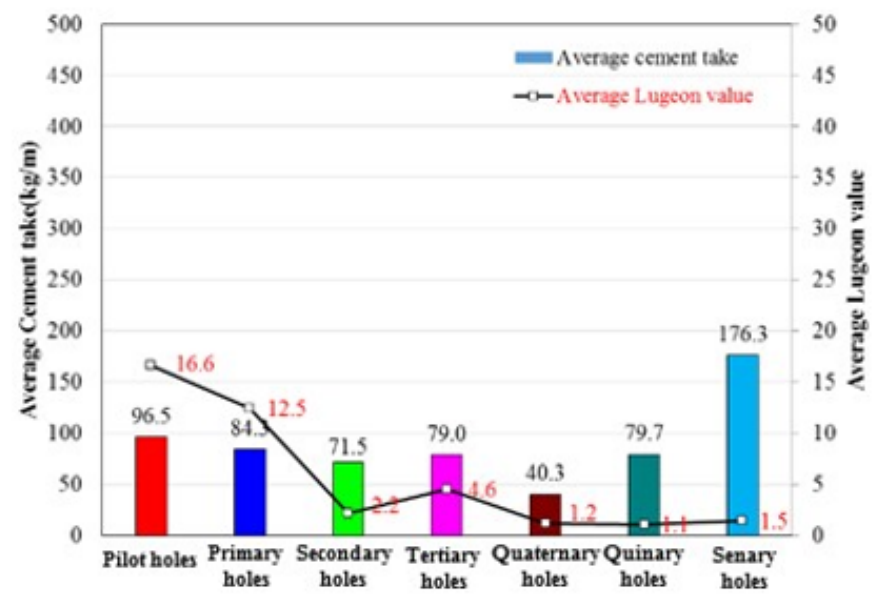

Fig. 10(d) Block 14

Figure 10

Lu and UCV in Each Step 


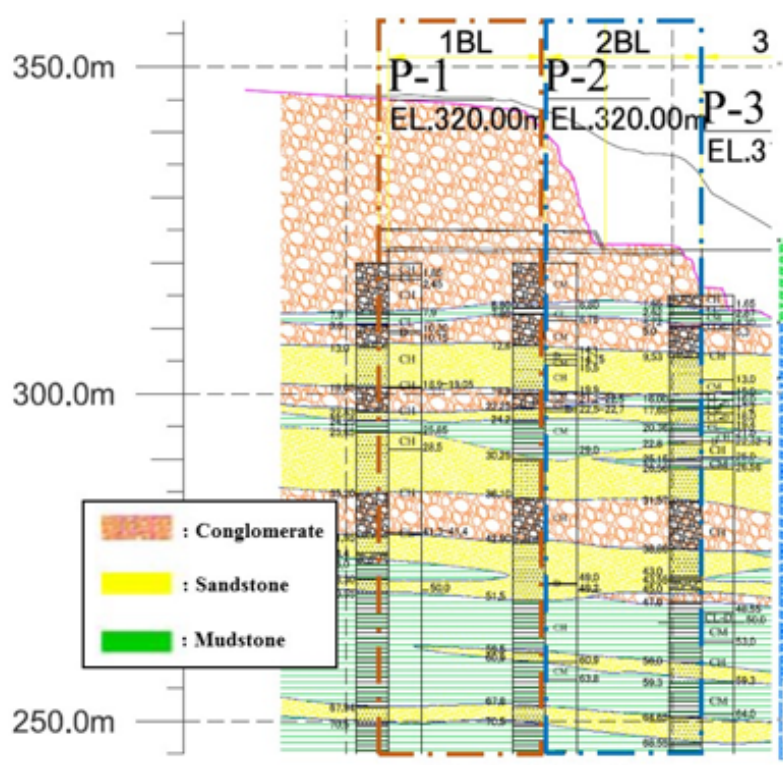

(a) Rock Kind

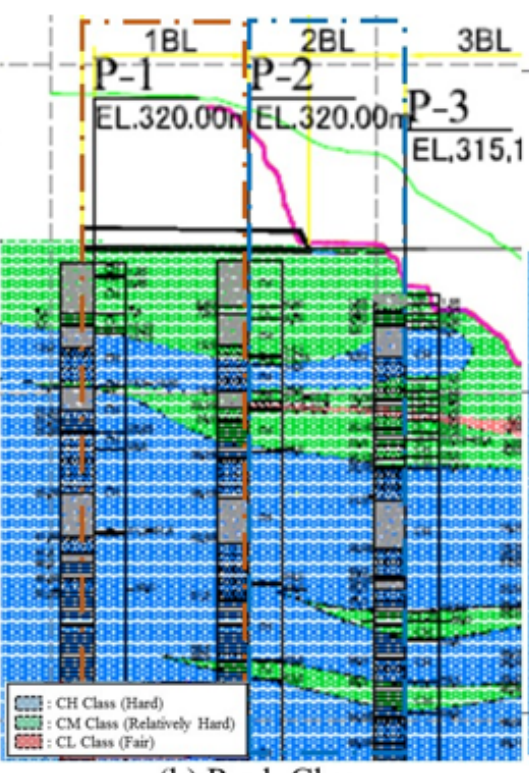

(b) Rock Class

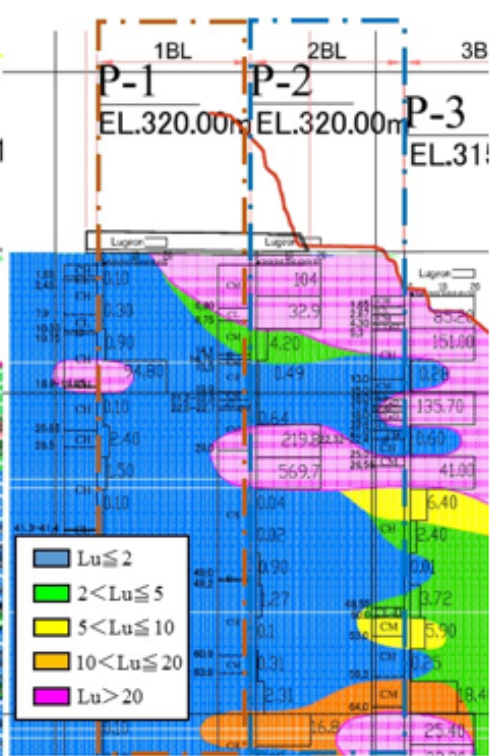

(c) Lugeon Value

\section{Figure 11}

Geological Characteristics in Blocks 1 and 2

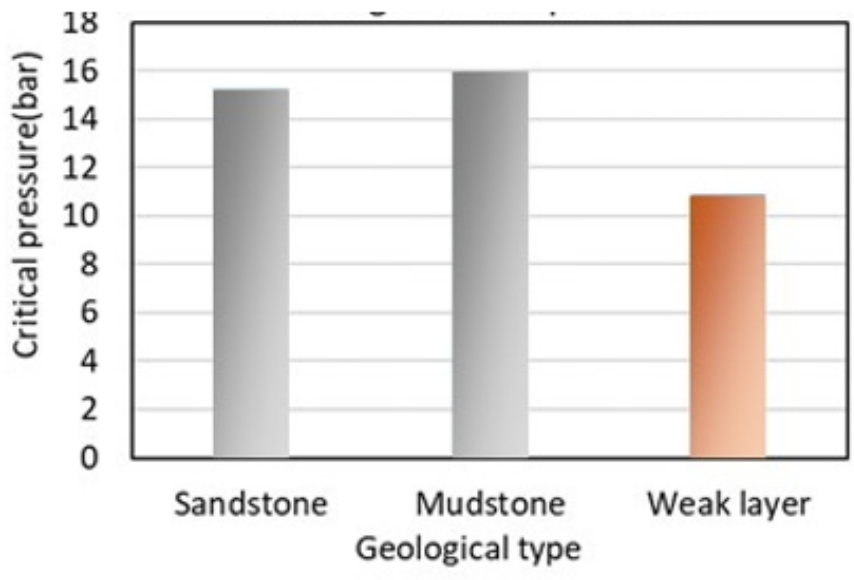

Fig. 12(a) CGP vs Rock Kind

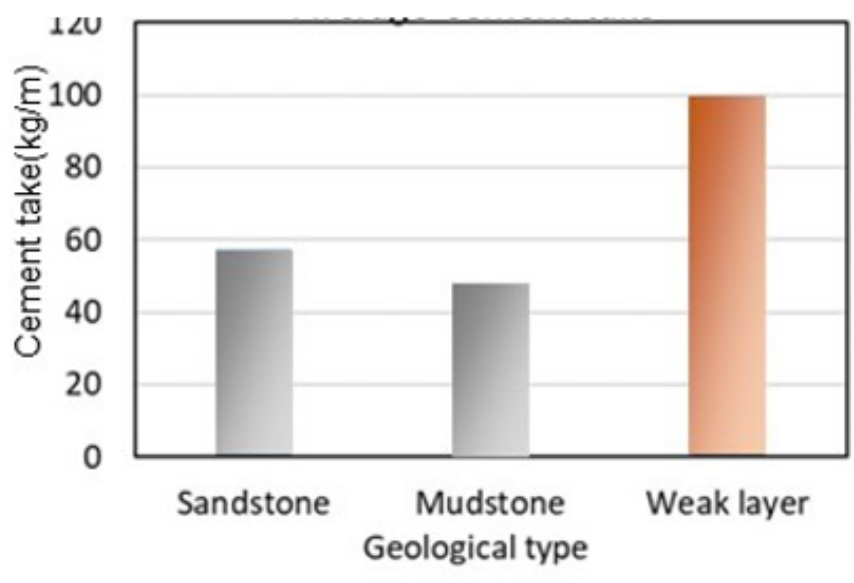

Fig. 12(b) UCV vs Rock Kind

Figure 12

Averaged CGP and UCV by Rock Species in Blocks 12 to 15 

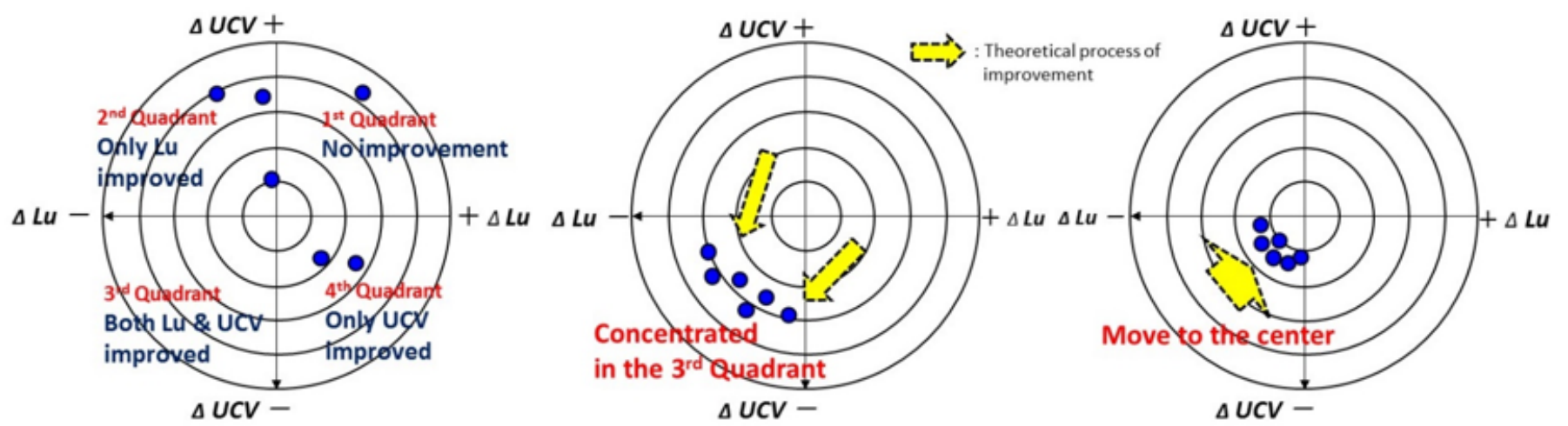

Fig. 13(a) Secondary to Tertiary

Fig. 13(b) Tertiary to Quarterly Fig. 13(c) Quarterly to Finally

\section{Figure 13}

Illustrative Image of Progress Management Method for Grouting with Axes of Lu and UCV

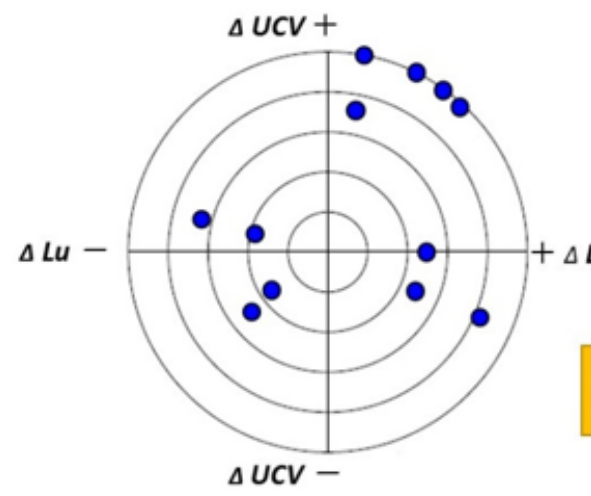

Fig. 14(a) Secondary to Tertiary

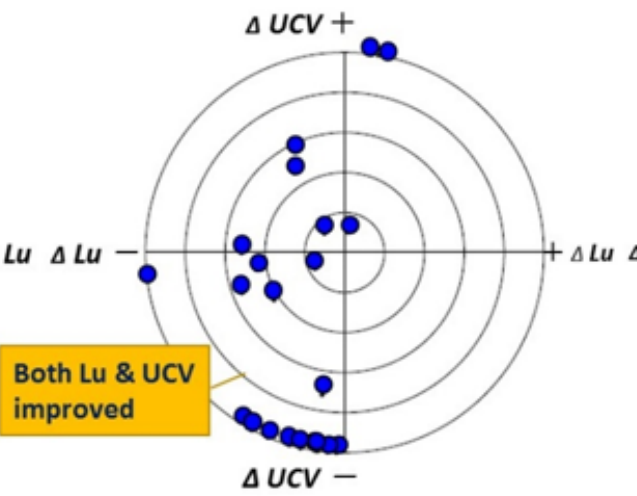

Fig. 14(b) Tertiary to Quarterly

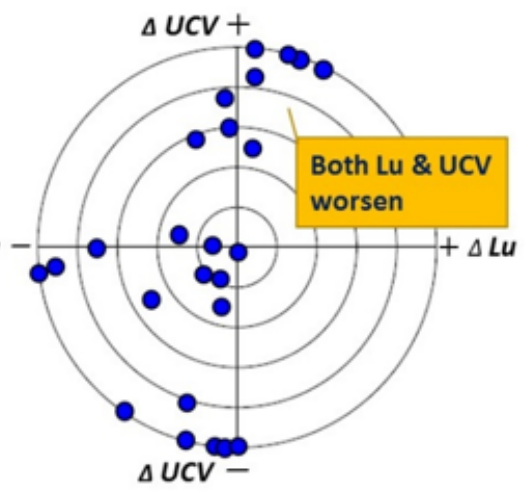

Fig. 14(c) Quarterly to Finally

\section{Figure 14}

Grouting Performance in Blocks 12 to 15 


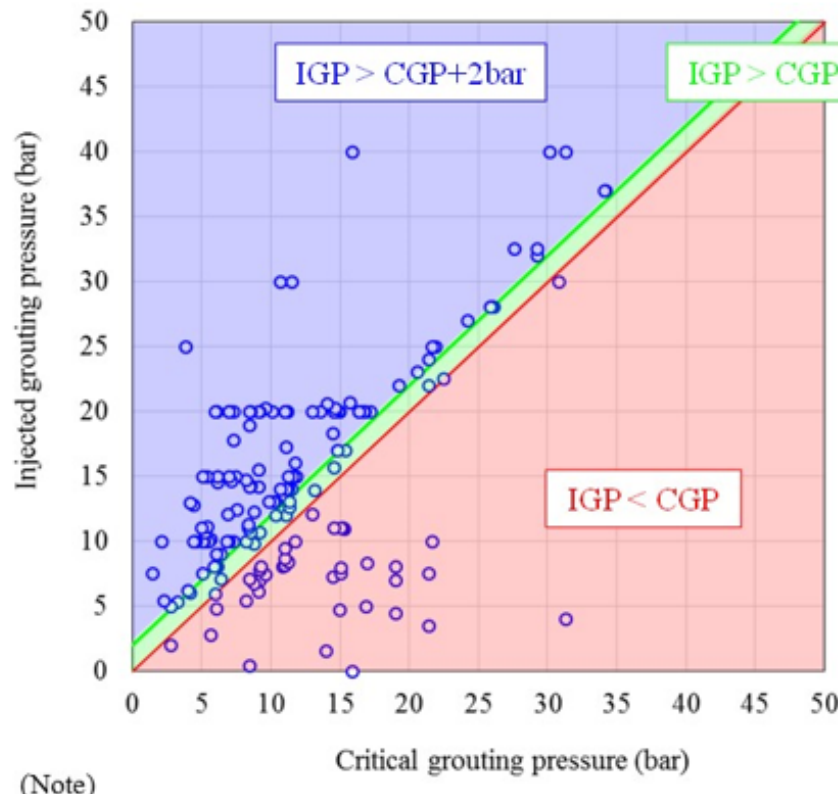

- Critical grouting pressure: The allowable grouting pressure set based on water pressure tests

- Injected grouting pressure: The actual grouting pressure crossing the GIN curve

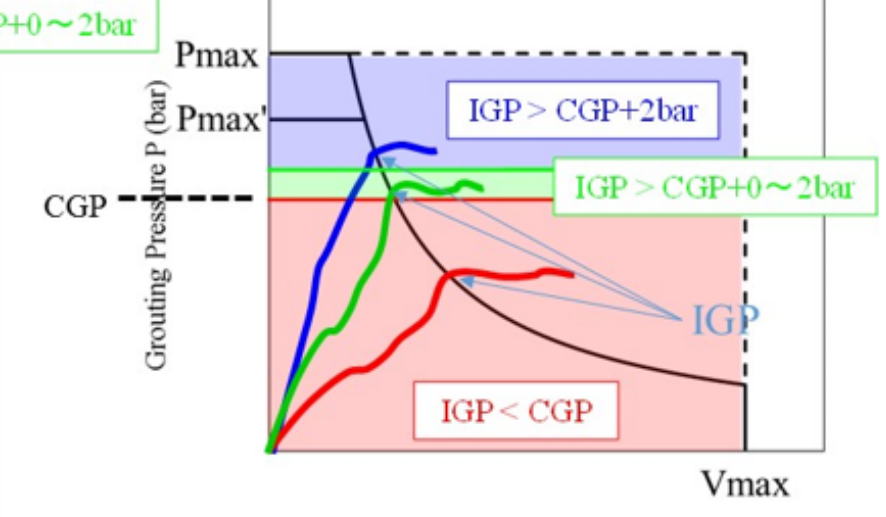

\begin{tabular}{|c|r|r|}
\multicolumn{3}{|c}{ Injected Volume V (liter/m) } \\
\hline Case & Number of stages & \multicolumn{1}{c|}{ Ratio } \\
\hline IGP $<$ CGP & 40 & $24 \%$ \\
\hline IGP $>$ CGP + 0 2 bar & 19 & $11 \%$ \\
\hline IGP $>$ CGP + 2bar & 110 & $65 \%$ \\
\hline Total & 169 & $100 \%$ \\
\hline
\end{tabular}

\section{Figure 15}

Correlation between IGP and CGP Based on Measured Data from Blocks 1, 2, 13 and 14 


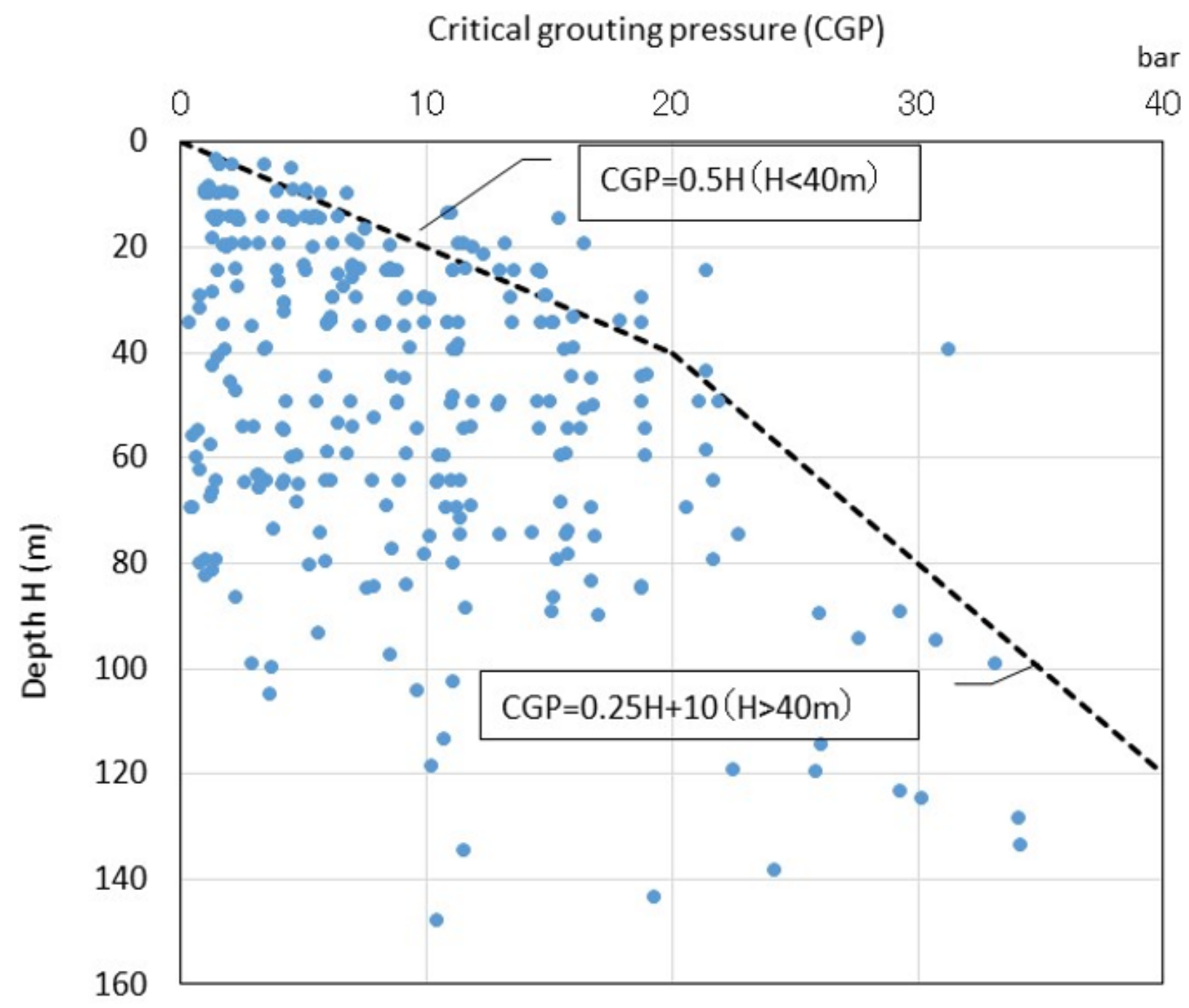

Figure 16

Correlation between CGP and Depth of Grouting Holes 


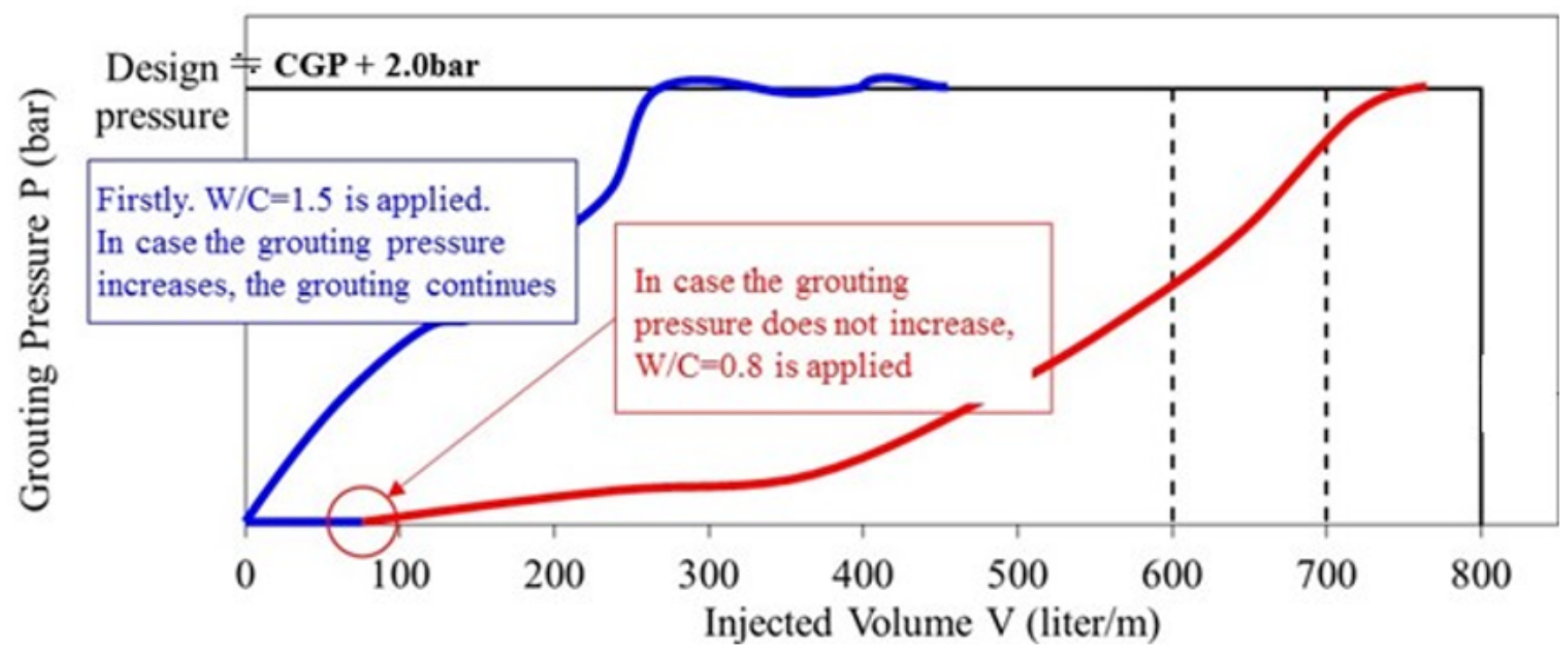

Figure 17

Grouting Specifications of Hybrid Method 


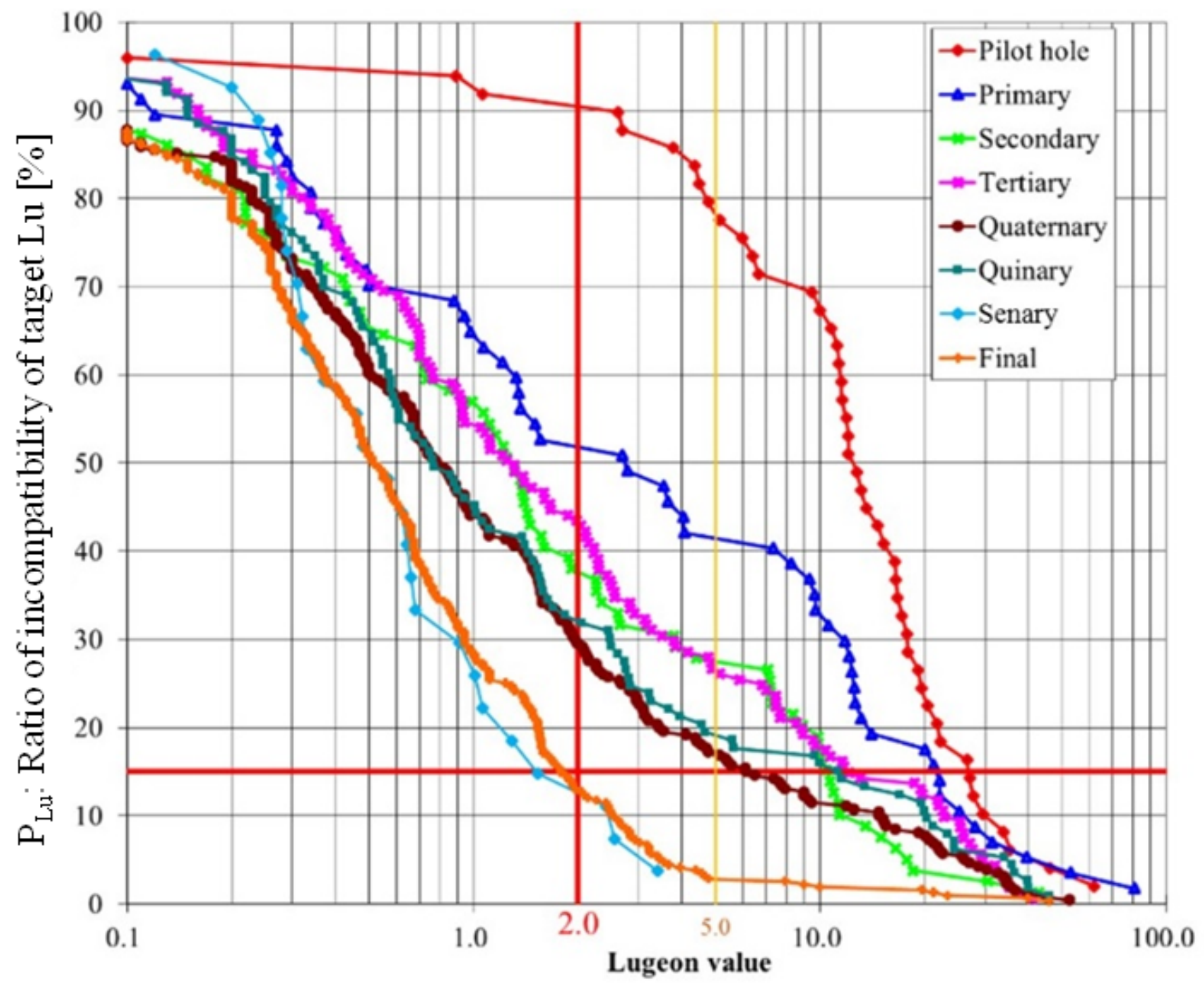

Figure 18

Ratio of Incompatibility of Target Lu in Blocks 18 to 22

Figure 19

Transition of Lu and UCV in Each Step of Blocks 18-22 


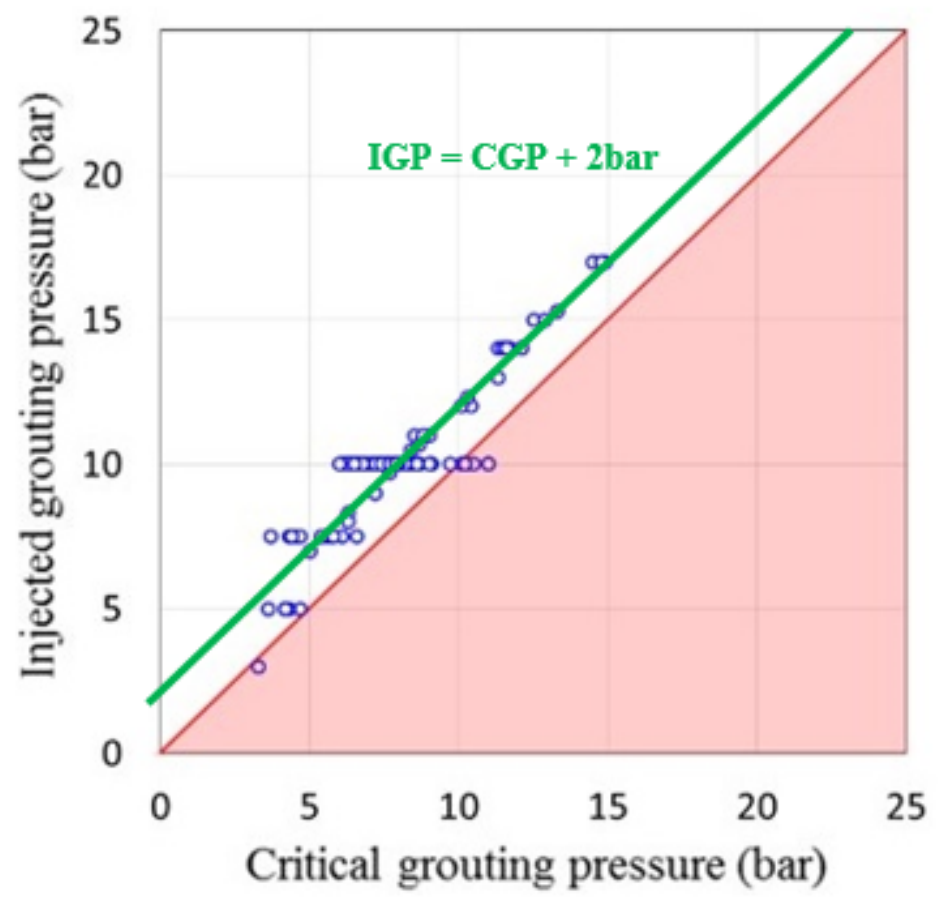

Figure 20

Correlation between CGP and IGP

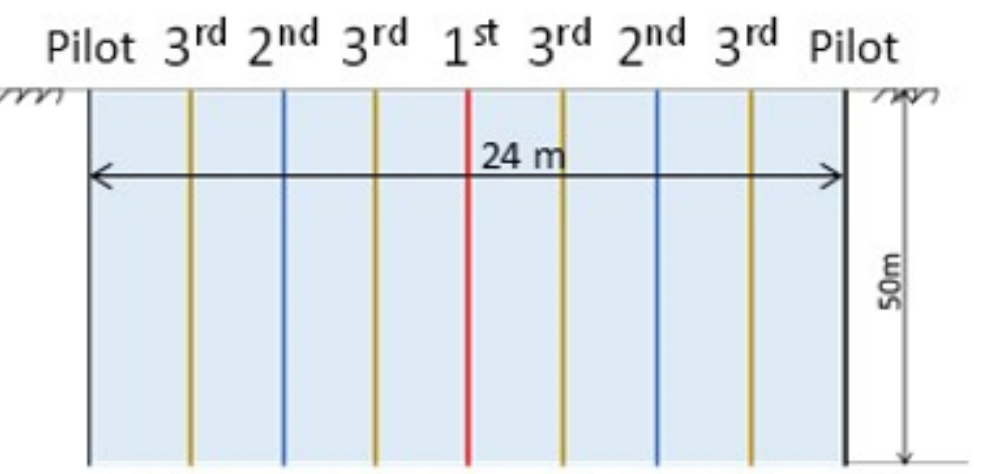

Normal Injection Holes $\left(1^{\text {st }}-3^{\text {rd }}\right)$

*in case of simple geological condition

\section{Figure 21}

Simple Geology Grout Patterns for Cost Estimation

Figure 22

Inhomogeneous Geology Grout Patterns for Cost Estimation 


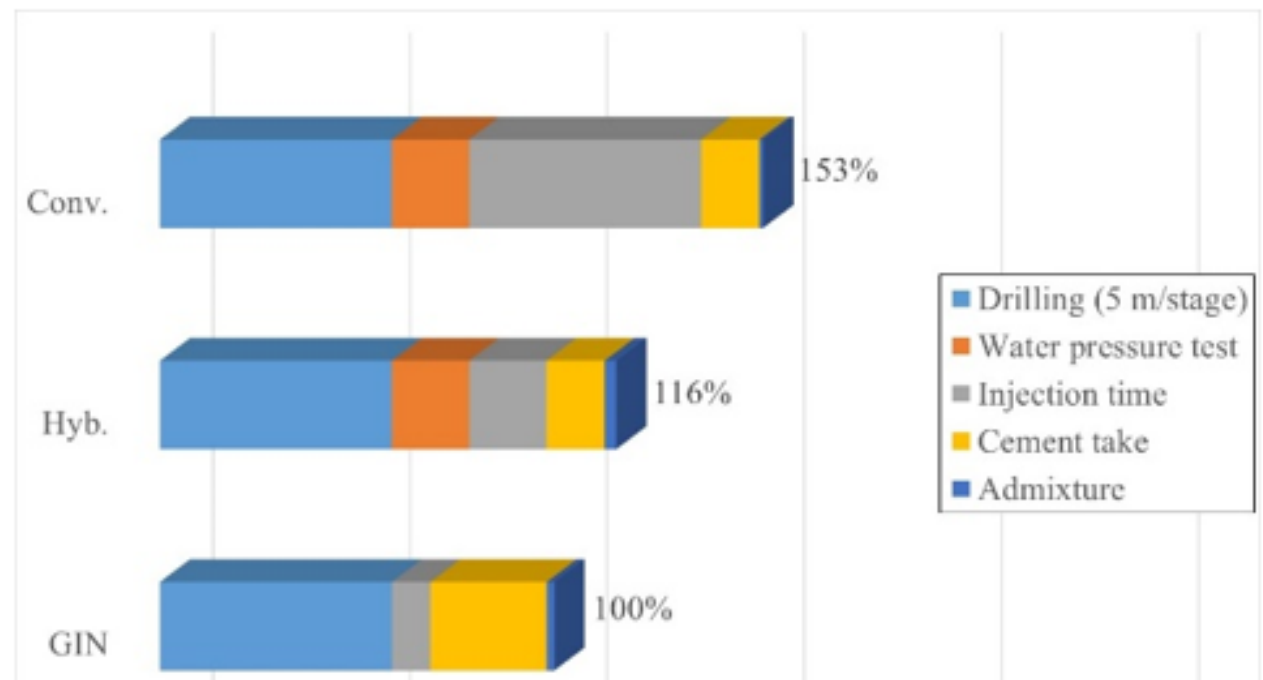

(Note) Total cost necessary for GIN at the simple geology is regarded as $100 \%$.
$0 \%$
$50 \%$
$100 \%$
$150 \%$
$200 \%$
$250 \%$

Fig. 23(a) Simple Geology

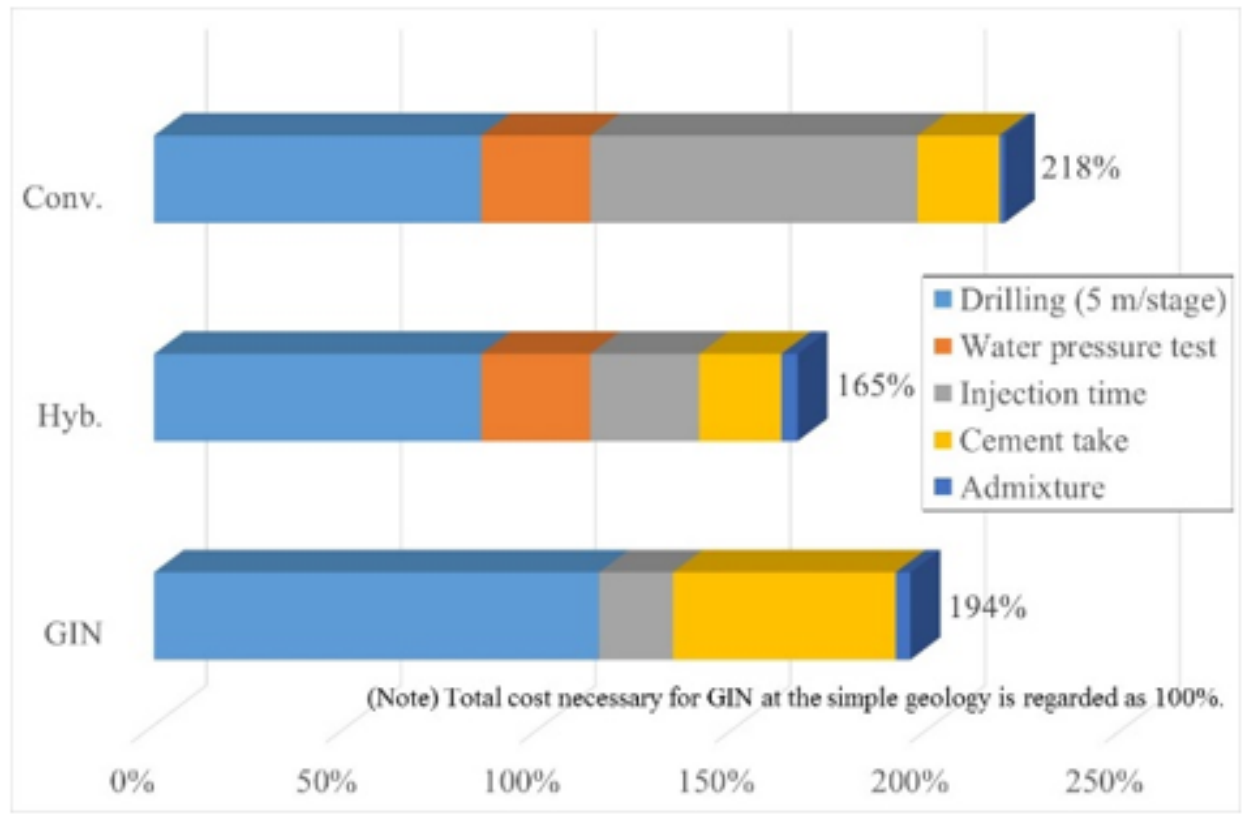

Fig. 23(b) Inhomogeneous Geology

\section{Figure 23}

Comparative Study Results of Each Method 


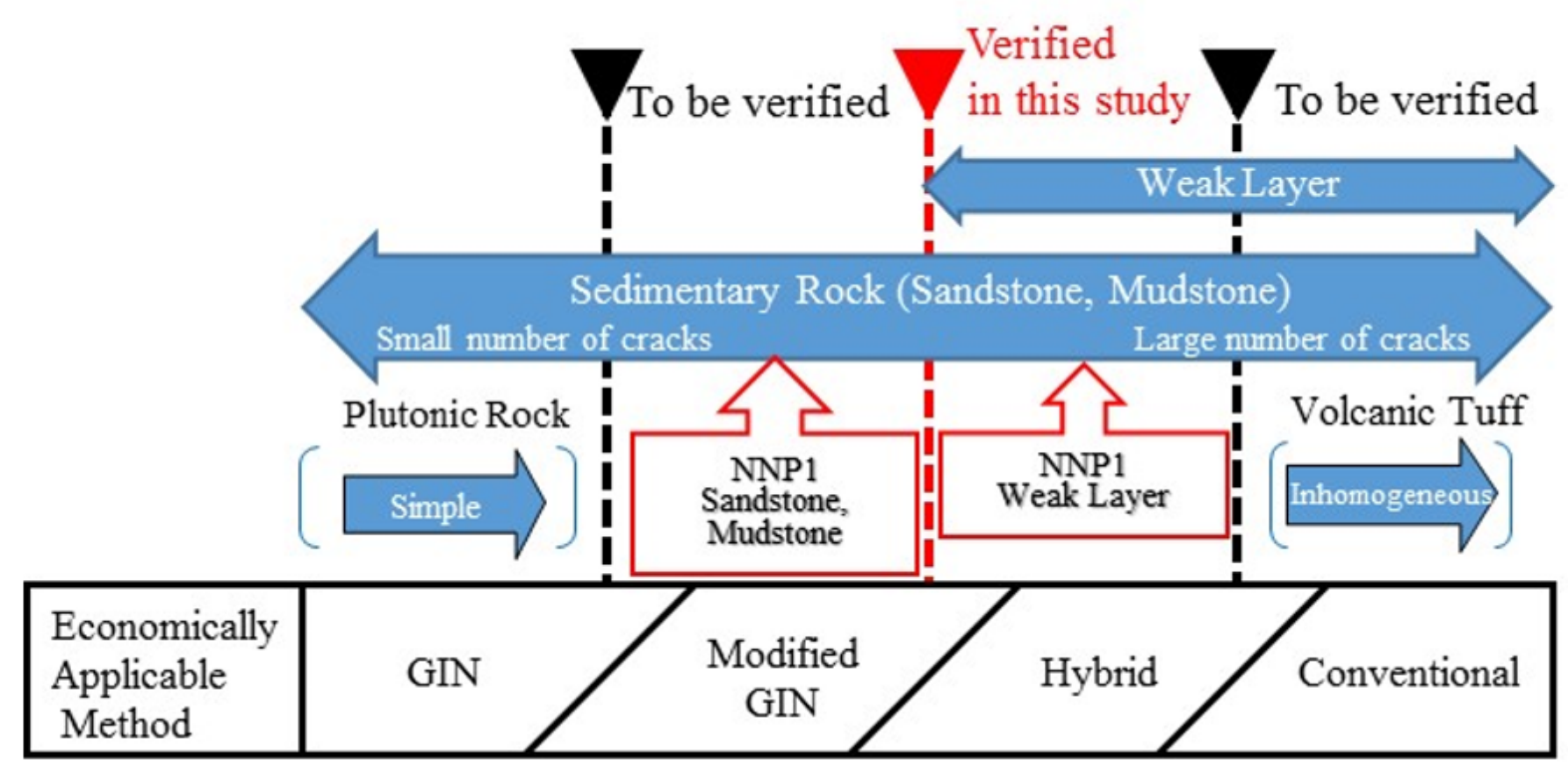

Figure 24

Proposal of Applicable Geological Conditions for Selecting Grouting Method 